\title{
Thorium isotopes tracing the iron cycle at the Hawaii Ocean Time-series Station ALOHA
}

2 Christopher T. Hayes ${ }^{\mathrm{a},{ }^{*},}$, Jessica N. Fitzsimmons ${ }^{\mathrm{a}, 1}$, Edward A. Boyle ${ }^{\mathrm{a}}$, David McGee ${ }^{\mathrm{a}}$, Robert F.

3 Anderson $^{\mathrm{b}}$, Rachel Weisend ${ }^{\mathrm{c}}$ and Peter L. Morton ${ }^{\mathrm{c}}$

$4 \quad{ }^{\mathrm{a}}$ Department of Earth, Atmospheric and Planetary Sciences, Massachusetts Institute of

5 Technology, Cambridge, MA

${ }^{\mathrm{b}}$ Lamont-Doherty Earth Observatory of Columbia University, Palisades, NY

${ }^{c}$ Department of Earth, Ocean, and Atmospheric Science, Florida State University, Tallahassee FL ${ }^{1}$ Now at Department of Oceanography, Texas A\&M University, College Station, TX *Corresponding author: cthayes@mit.edu

The role of iron as a limiting micronutrient motivates an effort to understand the supply and removal of lithogenic trace metals in the ocean. The long-lived thorium isotopes $\left({ }^{232} \mathrm{Th}\right.$ and ${ }^{230} \mathrm{Th}$ ) in seawater can be used to quantify the input of lithogenic metals attributable to the partial dissolution of aerosol dust. Thus, Th can help in disentangling the Fe cycle by providing an estimate of its ultimate supply and turnover rate. Here we present time-series (1994-2014) data on thorium isotopes and iron concentrations in seawater from the Hawaii Ocean Time-series

17 Station ALOHA. By comparing Th-based dissolved Fe fluxes with measured dissolved Fe inventories, we derive Fe residence times of 6-12 months for the surface ocean. Therefore, Fe inventories in the surface ocean are sensitive to seasonal changes in dust input. Ultrafiltration

20 results further reveal that Th has a much lower colloidal content than Fe does, despite a common

21 source. On this basis, we suggest Fe colloids may be predominantly organic in composition, at

22 least at Station ALOHA. In the deep ocean $(>2 \mathrm{~km}), \mathrm{Fe}$ approaches a solubility limit while Th,

23 surprisingly, is continually leached from lithogenic particles. This distinction has implications

24 for the relevance of Fe ligand availability in the deep ocean, but also suggests Th is not a good tracer for Fe in deep waters. While uncovering divergent behavior of these elements in the water column, this study finds that dissolved Th flux is a suitable proxy for the supply of Fe from dust

27 in the remote surface ocean. 


\section{Introduction}

Determination of the supplies of iron to the ocean is relevant to understanding Earth's climate and the ocean's ecology. Ocean storage of carbon dioxide is mediated by iron supply in large areas of the ocean where Fe is a limiting resource, both today (Moore et al., 2013) and during the ice ages (Martínez-García et al., 2014). Additionally, the marine distribution of diazotrophic phytoplankton that modulate the nitrogen cycle may be determined by Fe supply rates (Ward et al., 2013). Atmospheric dust is arguably the major source of Fe to the euphotic zone (Boyd et al., 2010; Conway and John, 2014; Jickells et al., 2005; Tagliabue et al., 2014). Debate on the sources of marine Fe ensues largely because the techniques to estimate the supply rate of Fe from dust in particular, or Fe residence times in general, are only beginning to be developed.

In this study, we assess the utility of thorium isotopes in seawater to provide rate information on the Fe cycle. By pairing ${ }^{232} \mathrm{Th}$, sourced from dust, with radiogenic ${ }^{230} \mathrm{Th}$ (or ${ }^{234} \mathrm{Th}$ ) that provides a timescale of thorium flux, one can make quantitative estimates of both the total dust flux to the ocean (Deng et al., 2014; Hsieh et al., 2011) and the flux of trace metals released by dust dissolution (Hayes et al., 2013a). Our study site is the Hawaii Ocean Timeseries Station ALOHA $\left(22^{\circ} 45^{\prime}\right.$ N, $158^{\circ}$ W) (Church et al., 2013; Karl and Lukas, 1996) in the subtropical North Pacific, where Asian dust is deposited in spring (Boyle et al., 2005; Hyslop et al., 2013; Prospero et al., 2003). Presenting time-series data spanning 20 yrs (1994-2014), we demonstrate that the behaviors of $\mathrm{Fe}$ and $\mathrm{Th}$ in seawater are consistent with a variable dust source to the surface ocean. Thorium-based fluxes indicate that the residence time of dissolved Fe in the upper $125 \mathrm{~m}$ of the water column is less than one year. In the sub-surface ocean $(>250$ 
$\mathrm{m})$, the thorium and iron cycles begin to diverge considerably. These divergences reveal new insights into the marine geochemistry of these elements.

\section{Background}

\subsection{Finding the timescale: thorium removal}

The rate information on trace metal cycling that we seek is obtained by exploiting the natural radioactive disequilibrium between insoluble ${ }^{230} \mathrm{Th}$ and its soluble parent ${ }^{234} \mathrm{U}$ in seawater. The oceanic distribution of ${ }^{234} U$ (half-life 245,620 yrs (Cheng et al., 2013)) is homogeneous within a few parts per thousand, as ${ }^{238} \mathrm{U}$ concentrations vary only with salinity (Owens et al., 2011) and ${ }^{234} \mathrm{U} /{ }^{238} \mathrm{U}$ ratios vary by less than 1 per mil (Andersen et al., 2010). Therefore, the decay of ${ }^{234} \mathrm{U}$ produces ${ }^{230} \mathrm{Th}$ at a known rate everywhere in the ocean. Due to its particle reactivity, thorium adsorbs onto sinking particulate matter, a process called scavenging, on a timescale of years to decades, much faster than ${ }^{230}$ Th decay (half-life 75,584 yrs (Cheng et al., 2013)).

Thus by comparing the amount of ${ }^{230} \mathrm{Th}$ that remains in seawater to the amount produced by U decay, one can calculate a removal timescale (Eq. 1, Fig. 1), or residence time $(\tau)$, of thorium in seawater. Equation 1 is written with radionuclide concentrations in terms of activity (decays per unit time per unit seawater). The denominator contains a ${ }^{230} \mathrm{Th}$ term to account for ${ }^{230}$ Th-decay, which, as mentioned above, can be neglected on the timescale of water column processes (for instance, seawater ${ }^{234} \mathrm{U}$ activity is $46.6 \mathrm{mBq} / \mathrm{kg}$ at salinity 35 , while typical ${ }^{230} \mathrm{Th}$ activities are $1-10 \mu \mathrm{Bq} / \mathrm{kg}$ ). This approach is analogous to that used with a more commonly used flux tracer, the shorter-lived ${ }^{234}$ Th (half-life 24.1 days). By the same principles, using its production rate from parent isotope ${ }^{238} \mathrm{U},{ }^{234} \mathrm{Th}$ inventories can also be used to determine the scavenging rate of Th in seawater (Buesseler et al., 1992; Coale and Bruland, 1985), except that 
${ }^{234} \mathrm{Th}$-decay is much more significant in the water column balance $\left({ }^{238} \mathrm{U}\right.$ activities being $\sim 40$ $\mathrm{mBq} / \mathrm{kg}$ compared to euphotic zone ${ }^{234} \mathrm{Th}$ activities of $30-40 \mathrm{mBq} / \mathrm{kg}$ ).

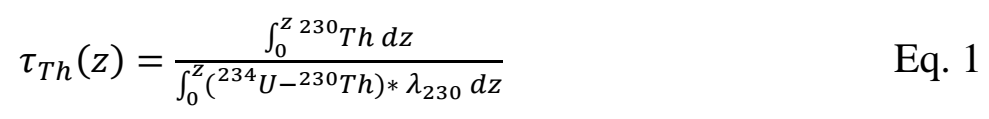

To meet the requirements of a steady-state assumption between source and removal terms, we calculate thorium residence times in an integrated sense, from the surface to a particular depth. Thus as one integrates deeper into the water column, the ${ }^{230} \mathrm{Th}$ inventories reflect longer timescales of removal. Residence times calculated in this way also neglect dispersal fluxes by ocean circulation. Lateral gradients in oceanic ${ }^{230} \mathrm{Th}$ concentrations are generally small (Hayes et al., 2015a), while large vertical gradients may make vertical fluxes significant, for instance due to upwelling (Luo et al., 1995).

\subsection{Finding the source: lithogenic metal fluxes}

The dominant isotope of seawater thorium is primordial and long-lived (half-life $14.1 \mathrm{x}$ $\left.10^{9} \mathrm{yrs}\right)^{232} \mathrm{Th}$. It is added to the ocean only through the partial dissolution of continental material, which in the context of Station ALOHA we consider to be primarily aerosol dust. Once in the water column, ${ }^{232} \mathrm{Th}$ is assumed to undergo scavenging removal (Fig. 1) at the same rate, i.e. with the same residence time, as ${ }^{230} \mathrm{Th}$ ( or ${ }^{234} \mathrm{Th}$ ), as scavenging tendencies are characteristic of all isotopes of an element. Assuming a steady state for Th concentrations, with knowledge of the Th residence time derived from ${ }^{230} \mathrm{Th}$, one can calculate the flux of dust-derived ${ }^{232} \mathrm{Th}$ necessary to support the observed ${ }^{232}$ Th inventory (Eq. 2). As in calculating thorium residence times, the derived dissolved ${ }^{232} \mathrm{Th}$ flux is reflective of the integrated depth zone, rather than at a particular depth. More details on ${ }^{232}$ Th flux calculations are reported by Hayes et al. (2013a).

$$
{ }^{232} \operatorname{Th} \operatorname{flux}(z)=\frac{\int_{0}^{z 232} T h d z}{\tau_{T h}(z)} \quad \text { Eq. } 2
$$


In comparison to the relative simplicity of the supply and removal terms in the thorium cycle, seawater iron cycling has many more terms to consider. These include biological uptake,

97 remineralization, redox chemistry, anthropogenic or hydrothermal sources, in addition to supply by dust and removal by scavenging (Fig. 1). Scavenging of Fe also occurs but at a different rate than that of Th. The utility of this element pair is their common source from dust. This is, of 100 course, an idealization of the "simple" thorium cycle. Th will be involved to some extent with 101 (perhaps inadvertent) uptake into and remineralization from organic matter (Barbeau et al., 2001; 102 Hirose and Tanoue, 1994). We have also observed a strong hydrothermal sink for Th in the 103 Atlantic (Hayes et al., 2015a) in addition to an abyssal source of Th from sediments in the North 104 Pacific (Hayes et al., 2013a). Nonetheless, particularly in the remote surface ocean well above 105 the seafloor, dust dissolution and scavenging appear to be the dominant terms for Th cycling. 106 Thus, in this manuscript we propose using dissolved ${ }^{232}$ Th flux as a proxy for the Fe released 107 during dust dissolution. This can be done with knowledge of the Fe/Th ratio in the dust and the 108 relative fractional solubility of the two elements $\left(\mathrm{S}_{\mathrm{Fe} / \mathrm{Th}}\right.$, Eq. 3). By weight, the Asian desert dust that undergoes long-range transport over the North

111 Pacific contains ${ }^{232}$ Th at $14.3 \pm 0.8 \mathrm{ppm}$, based on fine grained $(<8 \mu \mathrm{m})$ source materials 112 (McGee, 2009; Serno et al., 2014), and Fe at $3.8 \pm 0.4 \%$, based on a literature compilation by 113 Mahowald et al. (2005). Therefore, we assume the Fe/Th ratio in dust at Station ALOHA of 2660 $114 \pm 320 \mathrm{~g} / \mathrm{g}$ or $11,040 \pm 1450 \mathrm{~mol} / \mathrm{mol}$. These ratios are close to the average for the upper 115 continental crust of $\mathrm{Fe} / \mathrm{Th}=3271 \mathrm{~g} / \mathrm{g}=13,553 \mathrm{~mol} / \mathrm{mol}$ (Taylor and McLennan, 1995). 116 The relative fractional solubility of Fe and Th in dust is currently unconstrained. Hayes et 117 al. (2013a) assumed $\mathrm{S}_{\mathrm{Fe} / \mathrm{Th}}=1$ as a starting point, based solely on the similarly insoluble nature 
118 of these two elements in seawater. While much more work is needed to constrain this parameter,

119 here we continue to assume $\mathrm{S}_{\mathrm{Fe} / \mathrm{Th}}=1$, and our observations of the time-series variability in the

120 seawater $\mathrm{Fe} /{ }^{232} \mathrm{Th}$ ratio (section 4.4) support this assumption.

\subsection{Iron residence times}

We cannot rule out significant marine Fe sources by anthropogenic (e.g., derived from

123 fossil fuel combustion) aerosols, continental margin sediments, or deep-sea hydrothermal vents.

124 We can, however, pursue the notion that if dust were the only Fe source to the water column, the 125 comparison between measured dissolved Fe inventories to the source (dust-dissolved Fe flux) 126 would produce a measure of the turnover rate or residence time of dissolved Fe in seawater (Eq.

127 4). This residence time again represents the residence time within the integrated water column.

128 Additional sources of Fe, such as combustion aerosols or hydrothermal fluids, would cause the

129 dust-based Fe residence time to be an overestimate. Relevant to iron cycling, this residence time

130 provides a rough timescale over which one can expect Fe concentration to vary as a result of

131 variation in sources, such as springtime Asian dust events (Boyle et al., 2005).

139 September 2012 (HOE-DYLAN), May-June 2013 (HOE-PhoR-I), September 2013 (HOE-PhoR-

140 II) and March 2014 (HOE-BOE-I). Depth profiles for ${ }^{230} \mathrm{Th} /{ }^{232} \mathrm{Th}$ analysis were collected from 
141 the ship's Niskin bottle rosette, filtered with a $0.45 \mu \mathrm{m}$ Acropak cartridge filter, and acidified to $142 \mathrm{pH} 1.8$ with Savillex-distilled $6 \mathrm{M} \mathrm{HCl}$.

143 Filtered surface seawater $(0.4 \mu \mathrm{m})$ was collected for ${ }^{232} \mathrm{Th}$ (which requires smaller 144 volumes than for ${ }^{230} \mathrm{Th}$ ), as well as for dissolved Fe, using the trace-metal clean MITESS 145 sampler (Bell et al., 2002) at near daily time intervals on the 2012-2013 C-MORE cruises. 146 MITESS collection methods, including "Vane" sampling for Fe depth profiles, on the HOE 147 campaigns are discussed fully by Fitzsimmons et al. (in review). Within 3 hours of collection, the 148 seawater was filtered using $0.4 \mu \mathrm{m}$ polycarbonate track etch filters (PCTE, Whatman).

149 Particulate samples were immediately frozen, and dissolved filtrates were acidified to $\mathrm{pH} 2$ with 150 trace metal clean $\mathrm{HCl}$. The filters used for filtering MITESS water were analyzed for particulate

151 Fe and ${ }^{232} \mathrm{Th}$ (representing on average 0.7 liters of seawater).

On HOE-PhoR-II, cross flow filtration was performed to assess colloidal ${ }^{232} \mathrm{Th} /{ }^{230} \mathrm{Th}$

153 using protocols developed to study colloidal Fe (Fitzsimmons and Boyle, 2014a). Seawater was 154 pre-filtered at $0.45 \mu \mathrm{m}$ and, within 1-2 hours, pumped over a Millipore Pellicon XL filter made 155 of regenerated cellulose with a nominal molecular weight cutoff of $10 \mathrm{kDa}$, roughly equivalent to 156 an effective pore size of 10 nanometers. Both permeate and retentate fractions were analyzed to 157 determine any loss of Th by adsorption, which turned out to be minimal (88-100\% dissolved Th 158 recovery).

\subsection{Hawaii Ocean Time-series (HOT) seawater}

160 Seawater samples, typically 0.5 liter size, have been collected during the HOT program

161 for trace metal analysis at MIT periodically since 1997. Most of these samples were collected as 162 unfiltered water using the MITESS sampler (Bell et al., 2002) and subsequently preserved by 163 acidification to $\mathrm{pH} 2$ with $\mathrm{HCl}$. We report data from samples collected via ship-based MITESS 
164 collections as well as MITESS units deployed on a mooring (1997-2000, 2004-2005). In ship165 board sampling, a sample bottle filled with high-purity dilute $(\sim 0.001 \mathrm{M}) \mathrm{HCl}$ is lowered over 166 the side on a clean-wire and opened at depth, allowing 15-20 minutes for the bottle to be 167 completely flushed with the denser seawater, before bottle closure and sample retrieval. The 168 moored sampling worked similarly except that bottles were filled with stronger acid $(1 \mathrm{M} \mathrm{HCl})$ 169 prior to sampling. The moored sampling potentially posed a metal contamination risk due to the 170 effective stronger leaching of the HDPE bottles, increasing the chance for leached Th, for 171 example, to remain in the sample bottle at the time of collection. We report the moored sampler 172 data with a unique symbol in our figures and interpret them with caution. Further sampling 173 details are given by Boyle et al. (2005).

174 We also make use of literature seawater ${ }^{232} \mathrm{Th} /{ }^{230} \mathrm{Th}$ data, collected at Station ALOHA in 175 September 1994 (HOT-57), reported by Roy-Barman et al. (1996). 3.3 Thorium and iron analyses

177 Dissolved ${ }^{230}$ Th concentrations at Station ALOHA are as low as $10^{-18}$ moles per kilogram 178 seawater $\left(10^{-18} \mathrm{~mol}{ }^{230} \mathrm{Th}=0.1746 \mu \mathrm{Bq}\right)$. Therefore, for measurement by inductively-coupled 179 plasma mass spectrometry (ICP-MS), 4-5 liter water samples are required. Thorium 180 concentrations were determined by isotope dilution by spiking with ${ }^{229} \mathrm{Th}$ (not present in natural 181 seawater). Sample preparation (pre-concentration, acid digestion, and chromatographic 182 purification) was performed using published methods (Anderson et al., 2012; Auro et al., 2012). 183 A portion of the ${ }^{230}$ Th samples were prepared and analyzed at the Lamont-Doherty Earth 184 Observatory (L-DEO), using an Element XR single-collector ICP-MS. The remaining ${ }^{230} \mathrm{Th}$ 185 samples were prepared at the Massachusetts Institute of Technology (MIT) and analyzed using a 
186 Neptune Plus multi-collector ICP-MS at Brown University. Th-232 was also analyzed in samples 187 prepared for ${ }^{230} \mathrm{Th}$.

Analysis of ${ }^{232} \mathrm{Th}$, at $10^{-15} \mathrm{~mol}$ (i.e. femtomoles) per $\mathrm{kg}$ seawater, required smaller samples (200-800 mL) and was measured on archive HOT and HOE samples for which sample

190 volume did not allow ${ }^{230}$ Th determination. While not as prone to contamination as some other 191 trace elements, clean lab techniques were required to produce blanks that were consistent and 192 low enough to allow detection of the relatively small sample size of $\sim 20-40$ femtomoles ${ }^{232} \mathrm{Th}$.

193 Therefore, modifications of the cited procedures for Th analysis (Anderson et al., 2012; Auro et 194 al., 2012) were made. Instead of co-precipitation with added Fe, pre-concentration of ${ }^{232} \mathrm{Th}$ was 195 achieved using magnesium hydroxide co-precipitation, such as that described for $\mathrm{Pb}$ by Reuer et 196 al. (2003). Thorium was purified using a smaller amount (100 $\mu 1$ rather than $1 \mathrm{ml})$ of anion197 exchange resin (AG1-X8) on columns fashioned from Teflon shrink-tubing. Samples were 198 loaded onto $\mathrm{AG1}-\mathrm{X} 8$ resin in $8 \mathrm{M} \mathrm{HNO}_{3}$ and Th was eluted with $6 \mathrm{M} \mathrm{HCl}$ (instead of $12 \mathrm{M} \mathrm{HCl}$, 199 to reduce acid blank), following Edwards et al. (1987). Blank determinations were made on 125 $200 \mathrm{~mL}$ aliquots of acidified seawater samples whose ${ }^{232}$ Th content had been determined during 201 previous ${ }^{230}$ Th analysis. The mean procedural blank $(\mathrm{n}=6)$ was $3.5 \pm 1.6 \mathrm{fmol}{ }^{232} \mathrm{Th}$, resulting in 202 a detection limit of $4.8 \mathrm{fmol}{ }^{232} \mathrm{Th}$. Samples for seawater ${ }^{232} \mathrm{Th}$ were prepared and analyzed at 203 MIT, using a Micromass IsoProbe multi-collector ICP-MS with detection by a Daly-style ion 204 counter.

205 In this study, we refer to measured trace metal concentrations as dissolved (filtered at 0.4 206 or $0.45 \mu \mathrm{m})$, particulate $(>0.4 \mu \mathrm{m})$, or total (acidified unfiltered water). The "total" 207 concentrations in this sense are sometimes referred to as "total dissolvable", allowing for the 208 possibility that some forms of Th are not mobilized into solution by acidification to $\mathrm{pH} 2$ or 
209 collected with co-precipitation. Since our goal in interpreting seawater ${ }^{230} \mathrm{Th}_{\text {concentrations is to }}$ 210 determine scavenging rates based on uranium decay, we made small (0-10\%) corrections for the

211 dissolved ${ }^{230}$ Th released from dust (or lithogenic material in general). This correction is based on 212 measured dissolved ${ }^{232} \mathrm{Th}$ and a lithogenic ${ }^{230} \mathrm{Th} /{ }^{232} \mathrm{Th}$ mole ratio of $4 \times 10^{-6}$ (Roy-Barman et al., 213 2009). The corrected dissolved ${ }^{230}$ Th values are denoted as "xs".

214 Particulate ${ }^{232} \mathrm{Th}$ and particulate Fe, were analyzed at Florida State University by total 215 digestion of the filter samples and subsequent analysis by ICP-MS, using slightly modified 216 versions of published protocols (Ho et al., 2011; Morton et al., 2013; Upadhyay et al., 2009). In 217 brief, samples were microwaved (CEM MARS Xpress) for 40 minutes at $180^{\circ} \mathrm{C}$ with $\mathrm{HNO}_{3}$ and $218 \mathrm{H}_{2} \mathrm{O}_{2}$ (to digest the organic and less refractory biogenic and authigenic components) and $\mathrm{HF}$ (to 219 digest the more refractory lithogenic components). The detection limit (based on 3 standard 220 deviations of the digested acid blanks) for particulate ${ }^{232}$ Th was $8 \mathrm{fmol} / \mathrm{L}(\mathrm{n}=19)$ and the 221 particulate Fe detection limit was $0.2 \mathrm{nmol} / \mathrm{L}(\mathrm{n}=21)$. Dissolved Fe was measured by isotope 222 dilution after pre-concentration onto nitrilotriacetate resin on the Micromass IsoProbe ICP-MS at 223 MIT (Lee et al., 2011). Further details on Fe analyses are discussed by Fitzsimmons et al. (in 224 review).

Data presented in this study can be accessed in the Supplemental Material online.

\section{Results and Discussion}

\section{$4.1{ }^{230} \mathrm{Th}^{232}$ Th depth profiles to $1.5 \mathrm{~km}$}

231 water column for a sense of the type of data used to calculate thorium fluxes (Fig. 2). High

232 resolution depth profiles were analyzed in late July 2012, early June 2013 and late September

233 2013. The mixed layer depths during these sampling casts (based on $0.125 \mathrm{~kg} / \mathrm{m}^{3}$ density change) 
234 were 54, 33 and $53 \mathrm{~m}$, respectively, and below $100 \mathrm{~m}$ these profiles displayed little

235 distinguishing hydrography (Figs. 2C, 2D, 2E).

236 For dissolved ${ }^{232} \mathrm{Th}$ (Fig. 2A), there were increased concentrations near the surface,

237 minimum concentrations at the depth of maximum chlorophyll concentration (the DCM, 120-

$238140 \mathrm{~m}$ ), and a relatively constant local concentration maximum at 500-600 m depth. At

239 intermediate depths (900-1200 m), each profile exhibited smooth variations in concentration but 240 concentrations at the different sampling dates varied by up to $30 \%$.

The surface ${ }^{232} \mathrm{Th}$ maxima are consistent with aerosol dust as the major source of ${ }^{232} \mathrm{Th}$ to

242 Station ALOHA, as recognized by Roy-Barman et al. (1996). An interesting feature of these

243 high-depth resolution measurements is that the surface $(5 \mathrm{~m}){ }^{232} \mathrm{Th}$ concentration was lower than

244 that in the core of the mixed layer (25 $\mathrm{m}$ depth) at these three sampling times. This is perhaps

245 related to small-scale scavenging and export dynamics, or particle cycling in general.

246 The coincidence of the subsurface chlorophyll maximum and the minimum in ${ }^{232} \mathrm{Th}$ is

247 apparently a universal feature for lithogenic trace elements such as Al, Ti and Fe (Dammshäuser

248 et al., 2013; Fitzsimmons and Boyle, 2014b; Ohnemus and Lam, 2015). This was also true for

249 dissolved and particulate Fe at Station ALOHA during this study (Fitzsimmons et al., in review).

250 Increased particle aggregation efficiency, such as through the formation of fecal pellets, may

251 more efficiently scavenge dissolved ${ }^{232}$ Th from this depth.

252

Scavenged ${ }^{232}$ Th may be partially released through remineralization of particles from the

253 near-surface upon sinking to mesopelagic depths $(300-500 \mathrm{~m})$. Thus remineralization may be

254 responsible for some of the subsurface ${ }^{232} \mathrm{Th}$ maxima at $400-600 \mathrm{~m}$ depth. In support of this

255 view, this depth range coincides with a rapid increase in phosphate concentration and apparent 
(http://hahana.soest.hawaii.edu/hot/trends/trends.html). On the other hand, the attenuation of particulate organic carbon at Station ALOHA is most intense at shallower depths, between 100 and $200 \mathrm{~m}$ (Bishop and Wood, 2008).

The dominant basalts of the Hawaiian Islands (tholeiitic) are low in Th content, $0.8 \pm 0.4$ ppm, according to available data in PetDB (www.earthchem.org/petdb) (Lehnert et al., 2000). Nonetheless, with our seawater observations, we cannot fully rule out lateral input of Th from the Hawaiian Islands. For instance, dissolved Mn concentrations reach a maximum near $800 \mathrm{~m}$ depth at Station ALOHA (Boyle et al., 2005) that may reflect a coastal source of metals.

The variability in ${ }^{232}$ Th concentration at intermediate depths (900-1400 m) could be due to the effect of hydrothermal activity at the nearby Loihi seamount. The iron oxide particles associated with hydrothermal plumes strongly scavenge Th, and depleted deep-sea Th concentrations have been observed up to $1400 \mathrm{~km}$ away from a vent site in the Atlantic (Hayes et al., 2015a). While intermediate water ${ }^{232}$ Th variability suggests the influence of hydrothermal scavenging here, the effect is apparently too weak to perturb the near-linear ${ }^{230}{ }^{\mathrm{Th}}$ profiles (Fig. 2). Time-variability in the influence of the Loihi hydrothermal system on trace metals at ALOHA is discussed more fully by Fitzsimmons et al. (in review).

The ${ }^{230} \mathrm{Th}$ profiles also displayed interesting temporal variations. The theory of reversible scavenging contends that a steady-state is achieved between thorium adsorption and desorption on uniform particles that settle at a constant rate (Bacon and Anderson, 1982). Under these assumptions, one expects ${ }^{230}$ Th concentrations to increase linearly with depth with a boundary condition of zero concentration at the surface. While the observed depth profiles are essentially linear (Fig. 2B), it appears that mixing at the surface homogenizes ${ }^{230}$ Th concentrations to some depth. Interestingly, the layer of relatively homogeneous ${ }^{230}$ Th extends deeper than the density- 
280 defined mixed layer (30-50 m), down to the deep chlorophyll maximum (Fig. 2; see also report

281 by Barone et al. (2015)). This phenomenon is worthy of future time-series study. Potentially a

282 remnant of deep winter mixed layers (> $100 \mathrm{~m}$ ), the homogeneous surface ${ }^{230}$ Th layer could also 283 represent some combination of vertical mixing and enhanced scavenging related to export of 284 organic matter from the euphotic zone.

Another significant observation is that while the surface ${ }^{230}$ Th concentrations from June 286 and September 2013 were nearly identical $(1.2 \mu \mathrm{Bq} / \mathrm{kg})$, the surface ${ }^{230} \mathrm{Th}$ concentrations from 287 July 2012 were about a factor of 2 lower $(0.6 \mu \mathrm{Bq} / \mathrm{kg})$. This implies a relatively rapid change in 288 scavenging and/or export production. Future time-series studies are warranted to further assess 289 the short-term (daily-monthly) variability in euphotic zone ${ }^{230}$ Th concentrations and how closely 290 these changes can be correlated with organic matter export. In the next section, we assess what 291 changes in the removal timescale are implied by these results.

\subsection{Surface thorium residence times}

Residence times of dissolved ${ }^{230} \mathrm{Th}$ as described in section 2.1 using the 2012-2014

295 results are presented in Figure 3. In this assessment, we integrate production due to ${ }^{234} \mathrm{U}$ decay 296 (based on salinity) and the measured ${ }^{230}$ Th inventory to $150 \mathrm{~m}$ depth. This allows comparison to 297 Th residence times calculated on the basis of ${ }^{234} \mathrm{Th}:{ }^{238} \mathrm{U}$ disequilibrium established by previous 298 work at Station ALOHA, during April 1999-March 2000 (Benitez-Nelson et al., 2001) and June299 July 2008 (Buesseler et al., 2009). The ${ }^{234}$ Th results differ slightly from the approach used here 300 for dissolved ${ }^{230} \mathrm{Th}$ since the ${ }^{234} \mathrm{Th}$ fluxes are calculated using unfiltered seawater. Since 301 adsorbed ${ }^{230} \mathrm{Th}$ concentrations are on the order of $\sim 10-20 \%$ of total ${ }^{230} \mathrm{Th}$ (Roy-Barman et al., 302 1996), residence times based on total ${ }^{234}$ Th can be expected to be up to $10-20 \%$ greater than

303 those based on the dissolved phase only. The low percentage of adsorbed ${ }^{230} \mathrm{Th}$ appears to hold 
304 generally for the remote ocean (Hayes et al., 2015b), but it could be higher in coastal or marginal 305 seas with high terrigenous or riverine input (e.g., (Andersson et al., 1995)).

306 We also assessed the influence of vertical mixing on surface ${ }^{230} \mathrm{Th}$ inventories, which 307 could influence the derived residence time. Assuming a vertical mixing coefficient $\left(\mathrm{K}_{\mathrm{v}}\right)$ of $10^{-5}$ $308 \mathrm{~m}^{2} / \mathrm{s}$ (Charette et al., 2013), using a linear regression of the ${ }^{230} \mathrm{Th}$ depth profiles (from 150 to 300 $309 \mathrm{~m}$ ), we can calculate the ${ }^{230} \mathrm{Th}$ added to the upper $150 \mathrm{~m}$ by vertical mixing as $\mathrm{K}_{\mathrm{v}} \times \mathrm{dTh} / \mathrm{dz}$. The 310 results indicate that this vertical mixing term is $3-5 \%$ of the integrated production due to ${ }^{234} \mathrm{U}$ 311 decay in the upper $150 \mathrm{~m}$. Therefore we can assume that vertical mixing does not significantly 312 affect the ${ }^{230} \mathrm{Th}$ residence time estimates at Station ALOHA.

313 Nearly all of the thorium residence time estimates fall in the range of 1 to 3 years with no 314 evident seasonal cycle (Fig. 3). In the HOT climatology, organic carbon export at $150 \mathrm{~m}$ is 315 highest in May-August. While export seasonality is relatively weak in this oligotrophic, 316 subtropical location (Church et al., 2013), long-term monitoring has revealed episodic export 317 events related to diatom blooms and symbiotic cyanobacteria, typically in late July and early 318 August (Karl et al., 2012).

319 The concept of "residence time" used here is based on a steady-state assumption for 320 sources and sinks. Therefore with a residence time of $\sim 2$ years, one would not expect significant 321 variation in the removal timescale over a period of months. However, the range in observed Th 322 residence times for Station ALOHA indicates that this steady-state assumption is not quite 323 correct. More precisely, the steady-state for scavenging removal of Th appears to hold within a 324 factor of 2-3. The range in removal timescales observed based on ${ }^{230} \mathrm{Th}$ is similar to that based on $325{ }^{234} \mathrm{Th}$. Thus, it seems the rate of thorium scavenging can change dynamically at Station ALOHA 
326 possibly related to export pulses, but the data are consistent with a long-term average thorium

327 residence time of $2 \pm 1$ years in the upper $150 \mathrm{~m}$.

\subsection{Surface ${ }^{232}$ Th concentrations}

With relatively good control on the removal timescale of thorium, we turn to observed

variability in surface ${ }^{232}$ Th concentrations. Barring significant fluxes due to lateral circulation,

331 this variability represents the balance between removal by scavenging and input by dust. Smaller

332 volume requirements for analysis ( $<1$ liter) allowed us to investigate ${ }^{232}$ Th from daily, monthly 333 and decadal timescales.

Collected during a series of cruises in summer 2012 (HOE-DYLAN), daily-scale samples of $250 \mathrm{~mL}$ were analyzed for dissolved and particulate ${ }^{232} \mathrm{Th}$. Sample size required combining 336 the samples from 2-4 days for dissolved ${ }^{232} \mathrm{Th}$, contributing to some temporal smoothing.

337 Dissolved concentrations ranged from 45-90 fmol/kg (Fig. 4C). Particulate ${ }^{232} \mathrm{Th}$, although 338 measured at a higher, daily resolution, had a higher range of variability, from 10-290 fmol/kg. Of 339 the total seawater ${ }^{232}$ Th (dissolved + particulate) during HOE-DYLAN, on average $42 \%$ was in 340 the particulate phase (range $26-66 \%$ ). This fraction particulate is higher than that for ${ }^{230} \mathrm{Th}$ 341 ( 15\%, Roy-Barman et al., 1996) since particulate ${ }^{232}$ Th represents both adsorbed Th and 342 structural Th in mineral dust.

343 The decadal time-series observations (1994-2014) of total ${ }^{232} \mathrm{Th}$ (Fig. 4A) exhibit a range 344 in concentration $(\sim 50-300 \mathrm{fmol} / \mathrm{kg})$ that is consistent with the higher frequency observations of 345 particulate Th in 2012-2013. Since most of the data fall within the range of 50-150 fmol/kg, we 346 are not fully confident in the five observations of elevated concentrations (150-300 fmol/ $\mathrm{kg})$

347 observed in 1994, 1998, and 1999 samples. In particular, the 1998 and 1999 samples were 348 collected using the moored MITESS units, as discussed in section 3.2. Mooring-collected water 
349 at times had higher Th concentrations than contemporaneous ship-based sampling (Fig. 4) and

350 thus the possibility of contamination during sampling, sample storage, or sample analysis cannot

351 be fully discounted. In fact, the variable 1994 results from Roy-Barman et al. (1996) came from

352 multiple samples collected on the same Niskin bottle cast. Spatial variability, related to

353 mesoscale eddies, is another potential source of rapid changes in surface ${ }^{232} \mathrm{Th}$ concentration.

354 Conservatively excluding the elevated observations $>150 \mathrm{fmol} / \mathrm{kg}$, no significant temporal term 355 trend can be derived.

When all observations are placed on a monthly axis (Fig. 4B), there is little indication of

357 elevated surface ${ }^{232}$ Th concentrations during the spring (Mar-Jun) season of Asian dust transport

358 over the North Pacific. It appears that dissolved ${ }^{232}$ Th may be relatively constant throughout the 359 year, consistent with the Th residence times of $\sim 2$ yrs derived in section 4.2. Unfortunately, few

360 observations of dissolved ${ }^{232}$ Th have been yet made during the spring season when dust input can 361 increase by 2 orders of magnitude (Hyslop et al., 2013). Of course, these data are sparse, but they 362 do provide a baseline of variability against which future trace metal observations can be 363 measured.

$4.4 \mathrm{Fe} /$ Th ratio behavior in surface water and in colloidal content

Before applying the ${ }^{232} \mathrm{Th}$ flux technique, comparison of the time-series behavior of Fe

366 (Fitzsimmons et al., in review) and ${ }^{232} \mathrm{Th}$ is informative in terms of relative solubility and relative

367 removal rates (Fig. 5). This is possible because both elements have been analyzed on the same

368 samples from HOE-DYLAN, HOE-PhoR and many of the HOT archive samples.

In the context of daily, monthly and decadal variability, it appears that the ratio of total

370 and particulate $\mathrm{Fe} /{ }^{232} \mathrm{Th}$ tends to be at or above the dust-ratio of $11,040 \mathrm{~mol} / \mathrm{mol}$, while dissolved

$371 \mathrm{Fe} /{ }^{232} \mathrm{Th}$ is at or below the dust-ratio (Fig. 5A \& 5B). These observations are consistent with 
372 input at the dust $\mathrm{Fe} /{ }^{232} \mathrm{Th}$ ratio and a strong sink from biological uptake for Fe. Thus, the

373 dissolved phase is left depleted in Fe relative to ${ }^{232} \mathrm{Th}$, while the particulate phase becomes

374 enriched in biogenic Fe. The total Fe/Th ratio often exceeds the dust ratio as well, possibly

375 because biogenic particulate Fe may be efficiently recycled and thus may reside in the surface

376 longer than particulate Th. Interestingly, the samples from moored MITESS units (open symbols

377 in Fig. 5) had Fe/Th ratios quite close to the near-crustal ratio of Asian dust. This fact does not

378 necessarily exclude the possibility for Th contamination in these samples but does suggest any

379 potential metal contamination was of near-crustal composition.

The partitioning between dissolved and total/particulate $\mathrm{Fe} /{ }^{232} \mathrm{Th}$ centers on the dust ratio

381 (Fig. 5C). We interpret this to mean that the relative fractional solubility of Fe and ${ }^{232} \mathrm{Th}\left(\mathrm{S}_{\mathrm{Fe} / \mathrm{Th}}\right)$

382 is close to 1 . An alternate interpretation would be that ${ }^{232}$ Th is more efficiently leached from

383 dust, leaving the particulate phase enriched in $\mathrm{Fe} /{ }^{232} \mathrm{Th}$ and the dissolved phase depleted in

$384 \mathrm{Fe} /{ }^{232} \mathrm{Th}$. However, given the known ability for phytoplankton to efficiently utilize Fe from dust

385 sources (e.g., (Rubin et al., 2011)), the assumption of $\mathrm{S}_{\mathrm{Fe} / \mathrm{Th}}=1$ during dissolution followed by

386 rapid biological uptake of Fe seems more likely. It is difficult to assign a quantitative

387 uncertainty to the relative solubility with the existing data. The measured seawater Fe/ ${ }^{232} \mathrm{Th}$

388 ratios $(\mathrm{n}=30)$ are on average within $54 \pm 51 \%(1$ sigma $)$ of the Asian dust ratio. Therefore, the

389 relative solubility is likely close to 1 with less than $50 \%$ uncertainty, but $50 \%$ could be used as a

390 conservative uncertainty estimate $\left(\mathrm{S}_{\mathrm{Fe} / \mathrm{Th}}=1 \pm 0.5\right)$. Consideration of the size-partitioning of $\mathrm{Fe}$

391 and Th within the dissolved phase provides another constraint on the pathways these elements

392 take after being released by dust. This investigation was also used as an opportunity to

393 determine whether ${ }^{232} \mathrm{Th}$ and ${ }^{230} \mathrm{Th}$ have coherent speciation, as assumed for the ${ }^{232} \mathrm{Th}$ flux

394 method. Figure 6 presents these results based on measurements of ultra-filtered seawater from 
395 HOE-PhoR-II in September 2013. We define colloidal Th as dissolved $(<0.45 \mu \mathrm{m})$ minus 396 soluble $(<10 \mathrm{kDa})$.

Of the measured dissolved Th, $8-25 \%$ was found in the colloidal phase $(0.45 \mu \mathrm{m}-10 \mathrm{kDa}$

$398 \approx 0.01 \mu \mathrm{m})$. The total Th recovery during ultrafiltration was nearly complete $(88-100 \%)$,

399 implying that this $8-25 \%$ of dissolved Th was indeed colloidal in size, not an artifact of Th

400 sorption/loss to the ultrafiltration system. Furthermore, at least at $15 \mathrm{~m}, 130 \mathrm{~m}$ (DCM), and 1000

$401 \mathrm{~m}$, the colloidal percentage for ${ }^{232} \mathrm{Th}$ and ${ }^{230} \mathrm{Th}$ agreed within the uncertainty of the

402 measurements. This result implies coherent speciation of these thorium isotopes despite very 403 different sources, and it supports the use of ${ }^{230} \mathrm{Th}$ as a tracer for ${ }^{232} \mathrm{Th}$ removal. This coherent 404 speciation result agrees with previous measurements of the ${ }^{232} \mathrm{Th} /{ }^{230} \mathrm{Th}$ ratio of filtered $(<0.2$ 405 $\mu \mathrm{m})$ and ultrafiltered (<1 kDa) solutions from the Mediterranean Sea (Roy-Barman et al., 2002). The role of colloids in Th scavenging has much history and deserves a few words of 407 context. Early models of scavenging inferred that Th likely goes through a colloidal intermediate 408 before being scavenged by larger, sinking particles (Honeyman et al., 1988; Honeyman and 409 Santschi, 1989). Subsequent attempts at measuring colloidal Th focused largely on ${ }^{234}$ Th (see 410 review by (Guo and Santschi, 2007)), in part due to its use in quantifying organic matter export.

411 A generalization might be made that outside of the coastal ocean, colloidal ${ }^{234} \mathrm{Th}$ was found to be 412 a relatively small $(<15 \%)$ proportion of the total dissolved (e.g., (Guo et al., 1997; Huh and 413 Prahl, 1995; Moran and Buesseler, 1992)), which is also consistent with our ${ }^{230} \mathrm{Th}$ and ${ }^{232} \mathrm{Th}$ 414 results. Recent observations from the North Atlantic (Hayes et al., 2015b), however, observed 415 scavenging characteristics consistent with a strong role for Th colloids as predicted by the 416 "colloidal pumping hypothesis" of Honeyman and Santschi (1989), even at open-ocean particle 
417 concentrations of $<10 \mu \mathrm{g} / \mathrm{kg}$ seawater. Further observations on the geographic distribution of 418 colloidal Th are clearly warranted.

419 Our paired observations of Th and Fe size partitioning nonetheless provide additional 420 information on their physicochemical speciation in a comparative sense. Dissolved Fe has a 421 much higher colloidal content at ALOHA than Th (Fig. 6). Above the DCM, dissolved Fe can be $422>50 \%$ colloidal. In the deeper water column, to $1.5 \mathrm{~km}$ depth, colloidal Fe is relatively constant 423 at $40 \%$ (with the exception of one sample $<10 \%$ colloidal at $650 \mathrm{~m}$ ). Since Fe and ${ }^{232} \mathrm{Th}$ are 424 apparently solubilized from dust with equal fractional solubility, this difference in size-speciation 425 is most likely also due to the selective uptake or complexation of Fe by organic substrates.

426 Ligands, in the form of macromolecular organic molecules or organic colloidal particles, most 427 likely complex Fe released from dust quite rapidly in the upper water column (Bressac and 428 Guieu, 2013; Mendez et al., 2010). We hypothesize that organic Fe-binding ligands are 429 predominantly responsible for converting such a large percentage of dissolved Fe to colloidal 430 size. The inorganic speciation of Th in seawater is largely hydroxo- complexes (Santschi et al., 431 2006). Other similarly hydrolyzable metals such as Al and Ti do not have significant colloidal 432 components (Dammshäuser and Croot, 2012).

Similar to $\mathrm{Al}$ and $\mathrm{Ti}$, the abundance of colloidal ligands (>10 $\mathrm{kDa})$ with an affinity to 434 complex Th must also be small compared to the source of dissolved Th from dust. This finding 435 does not necessarily contradict previous evidence for significant organic complexation of Th in 436 seawater (Santschi et al., 2006). It does require, however, that any significant Th complexation is 437 done by small $(<10 \mathrm{~nm})$, low-molecular weight organic molecules, at least in the subtropical $438 \quad$ North Pacific. 
Greater uptake of Fe into the colloidal phase is another piece of evidence that suggests that dissolved Fe is cycled more rapidly than Th in the upper water column. The innovation of

441 the ${ }^{232}$ Th flux method is our ability to be quantitative about the rates of Fe removal, which are 442 presented in the next section.

\subsection{Iron residence times}

Using the 2012-2013 ${ }^{230}$ Th profile data, we extend our calculations for Th residence time

the surface and the DCM is 1-2 years. The Th residence times increase nearly linearly with integration depth to 14 years for the average residence time between the surface and $1.5 \mathrm{~km}$. We do not plot integrated values shallower than the DCM ( 120 m) on the assumption that steadystate Th scavenging may not apply under the conditions of stronger mixing and organic matter export within the euphotic zone. Dividing the integrated dissolved ${ }^{232} \mathrm{Th}$ inventories by these residence times gives our estimate of dissolved ${ }^{232} \mathrm{Th}$ flux, as a function of integration depth, in Fig. 7B.

In June and Sept. 2013, the dissolved ${ }^{232}$ Th flux increased with integration depth and 454 began to level-off around $500 \mathrm{~m}$. This pattern reflects that, at these times, the inventory of 455 dissolved ${ }^{232} \mathrm{Th}$ increased with integration depth slightly more quickly than the increase in Th 456 residence time with depth. Interestingly, in July 2012, the dissolved ${ }^{232} \mathrm{Th}$ flux decreased with 457 integration depth, reflecting that the Th residence time increased more quickly than the dissolved $458{ }^{232}$ Th inventory, essentially because the mixed layer ${ }^{230} \mathrm{Th}$ concentrations were exceptionally low 459 at this time. Estimated ${ }^{232}$ Th fluxes are clearly quite sensitive to short-term variability in 460 scavenging rates. We suggest further time-series analysis along with modelling efforts that 461 contain circulation and realistic particle fluxes to determine more quantitatively the sensitivities 
462 involved in calculating dissolved ${ }^{232}$ Th fluxes during moderate changes in scavenging rates and 463 dust input.

464 The three flux profiles converge around $1000 \mathrm{~m}$ depth. This is encouraging that over 465 longer integration times, 10-15 years in this case, we estimate consistent lithogenic metal fluxes 466 at multiple time points. Using Eq. 1, the dissolved ${ }^{232}$ Th fluxes are simply converted to dust467 dissolved Fe fluxes, using $\mathrm{S}_{\mathrm{Fe} / \mathrm{Th}}=1$ and $(\mathrm{Fe} / \mathrm{Th})_{\text {dust }}=11,040 \mathrm{~mol} / \mathrm{mol}$, shown in the second $\mathrm{x}-$ 468 axis in Fig. 7B. The depth profiles of dissolved Fe concentrations from the same sampling 469 campaigns are shown in Fig. 7C (Fitzsimmons et al., in review). Finally, using Eq. 2, by 470 integrating Fe inventories and dividing by the dust-dissolved Fe fluxes, we estimate the residence 471 time of dissolved Fe, as a function of integrated depth in Fig. 7D. In the upper $250 \mathrm{~m}$, the residence time of dissolved Fe is 6 months to 1 year, again 473 assuming that the sole source of Fe to the surface ocean at Station ALOHA is aerosol dust 474 deposition. This range agrees well with the 6 month residence time estimated previously at 475 Station ALOHA (Boyle et al., 2005), and with other estimates of surface ocean dissolved Fe 476 residence times from the Atlantic based on measured Fe concentrations and assumptions about 477 soluble aerosol deposition (Bergquist and Boyle, 2006; Jickells, 1999; Ussher et al., 2013). With 478 such fast turnover times, dissolved Fe concentrations in surface waters can be expected to vary 479 on monthly to yearly timescales with changes in the seasonal input of dust from Asia. This is in 480 fact exactly what was observed over the HOT and HOE time-series (Fitzsimmons et al., in 481 review).

Available aerosol data suggest that Asian dust transport over the North Pacific had no 483 significant long-term trend from 1981 to 2000 (Prospero et al., 2003) and perhaps a 6\% decline 484 over the past 10 years (Hyslop et al., 2013). Because of a nearly immediate impact on surface 
485 water Fe concentrations and the associated ecological consequences, it is important to monitor 486 future changes in Fe sources. Sources such as Asian desert dust in our changing climate may 487 vary independently of other Fe sources such as combustion aerosols.

As one integrates further from $250 \mathrm{~m}$ to $1500 \mathrm{~m}$, while the dissolved Fe fluxes change

489 only moderately, the dissolved Fe residence times increase quickly to about 10 years at $1500 \mathrm{~m}$

490 depth. This is due to the large increase in Fe concentrations at these depths due to

491 remineralization of Fe from sinking organic material and some portion of Fe accumulated and

492 transported to ALOHA laterally via deep ocean circulation. There is potentially additional input

493 of $\mathrm{Fe}$ at $\sim 1 \mathrm{~km}$ depth due to Loihi hydrothermal activity. Additional lateral sources would cause

494 our dust-based dissolved Fe residence time to be an overestimate, implying even faster

495 timescales of Fe removal. On the other hand, as discussed in the next section, the 10 year Fe

496 residence time at $1500 \mathrm{~m}$ could as well be an underestimate, if the geochemical cycles of Th and

497 Fe become decoupled at greater depths where dust dissolution is no longer the most significant 498 source of dissolved Fe.

4.6 Fe and Th decoupling in the deep ocean

501 metal cycling due to aerosol deposition and export production. We can extend our analysis of $\mathrm{Fe}$

502 and Th into the deep ocean (4.5 km water depth at Station ALOHA) to learn about the

503 geochemistry of these elements over decadal-to-centennial timescales. In Figure 8, we compiled

504 available deep profiles from Station ALOHA for dissolved Fe (Boyle et al., 2005; Fitzsimmons

505 et al., in review; Morton, 2010) and dissolved ${ }^{232}$ Th and ${ }^{230}$ Th (this study; Roy-Barman et al.

506 (1996)). 
Variability in dissolved Fe at $1-1.5 \mathrm{~km}$ is clearly apparent, likely due to hydrothermal

508 inputs. Below $1.5 \mathrm{~km}$ depth, Fe, ${ }^{232} \mathrm{Th}$, and ${ }^{230} \mathrm{Th}$ display relatively constant profile shapes, at

509 least during the sparse sampling dates. From $2 \mathrm{~km}$ depth to the bottom, dissolved Fe is nearly

510 constant or slightly decreases with depth to about $0.4 \mathrm{nmol} / \mathrm{kg}$, while dissolved ${ }^{232} \mathrm{Th}$ actually

511 increases with depth from 50 to $180 \mathrm{fmol} / \mathrm{kg}$ below $3000 \mathrm{~m}$. This divergence in profile shape

512 already suggests a decoupling of the behavior of these elements in the deep ocean.

513 The deep ocean appears to contain an additional source for ${ }^{232} \mathrm{Th}$. This source is

514 potentially related to resuspension of diagenetically-altered sediments at the seafloor (Hayes et

515 al., 2013a; Okubo et al., 2012). The bottom-increase in ${ }^{232} \mathrm{Th}$ begins nearly $2 \mathrm{~km}$ above the

516 seafloor, much higher than typical benthic vertical mixed layers (50-100 m) (Richards, 1990).

517 This phenomenon, as observed with km-scale nepheloid layers (McCave, 1986), suggests that

518 the ${ }^{232} \mathrm{Th}$ at abyssal depths of Station ALOHA is being mixed in laterally from locations where

519 isopycnals impinge on surrounding bathymetry.

Also related to bottom sediment resuspension, the July 2012 profile of ${ }^{230} \mathrm{Th}$ displays a

521 negative concentration anomaly, or deficit of ${ }^{230} \mathrm{Th}$, with respect to the linear profile near the

522 seafloor (Fig. 8C). This bottom ${ }^{230}$ Th deficit is indicative of enhanced bottom scavenging as

523 observed in many parts of the deep North Pacific (Hayes et al., 2013b; Okubo et al., 2012). It is

524 non-intuitive that a bottom layer where the scavenging removal of Th is enhanced compared to

525 the overlaying water column would also be a strong source of ${ }^{232} \mathrm{Th}$. The resuspension of bottom

526 sediments may produce such a strong release of ${ }^{232}$ Th that this source more than compensates for

527 enhanced scavenging. Another contributing factor may be that the resuspended thorium could

528 have a much higher ${ }^{232} \mathrm{Th} /{ }^{230} \mathrm{Th}$ ratio than the water column due to age-decay of ${ }^{230} \mathrm{Th}$ in the

529 sediments. 
Dissolved Fe, on the other hand, appears unaffected by bottom processes, displaying only

531 a slight decrease in concentration with depth (Fig. 8A). The slight decrease with depth may be

532 related to scavenging of Fe as deep water masses age (Bruland et al., 1994). If we extend our

533 integrated residence time approach to the deep Fe profile at Station ALOHA (Fig. 9), we derive a

534 whole ocean residence for dissolved Fe of only 30 years. This is significantly shorter than the

535 100-300 year estimates of the ocean residence time for dissolved Fe based on deepwater

536 scavenging (Bergquist and Boyle, 2006; Bruland et al., 1994). This discrepancy must arise

537 because the deep ocean source of ${ }^{232}$ Th does not add dissolved Fe to the water column at a

538 crustal ratio, unlike what occurs during near-surface dust dissolution. Thus, the ${ }^{232}$ Th flux

539 method for Fe residence times probably should not be extended to the deep ocean.

540 The question remains: how is an element like Th, a trace component of continental

541 material, added to the deep ocean without a simultaneous release of a major crustal element like

542 Fe? The answer is likely related to solubility.

543 Dissolved Fe in the deep central North Pacific at $\sim 0.5 \mathrm{nmol} / \mathrm{kg}$ has been found to be at

544 near solubility equilibrium with Fe(III) hydroxide (Kitayama et al., 2009; Kuma et al., 2003).

545 These studies determine Fe(III) solubility by adding gamma-emitter ${ }^{59} \mathrm{Fe}$ (III) to filtered seawater,

546 allowing the solutions to come to solubility equilibrium with Fe(III) hydroxide over several

547 weeks, subsequently filtering the seawater and then counting the ${ }^{59} \mathrm{Fe}$ gamma-activity on the

548 final filtrate. The observed $\sim 0.5 \mathrm{nmol} / \mathrm{kg}$ solubility is elevated over Fe solubility in inorganic

549 seawater because of the presence of organic ligands (Liu and Millero, 2002). Thus, since the

550 deep Pacific is in a near saturation state, dissolved Fe can no longer be expected to increase, even

551 in the presence of increasing Th concentrations. 
A problem with this argument is that electrochemically-determined Fe ligand concentrations at Station ALOHA are up to $2 \mathrm{nmol} / \mathrm{kg}$, well in excess of dissolved $\mathrm{Fe}$ concentrations (Rue and Bruland, 1995), as found in most of the world ocean (Gledhill and Buck, 2012). However, it may not be kinetically appropriate to compare Fe ligand concentrations directly with seawater solubility. In either estimation, deepwater dissolved Fe is at least close to (within the same order of magnitude) our best estimates of Fe solubility.

While much less in known about Th solubility in seawater, our large underestimate of Fe residence time in the deep ocean implies that the deep North Pacific, with Th at $\sim 180 \mathrm{fmol} / \mathrm{kg}$, is below Th solubility equilibrium. Near seawater $\mathrm{pH}$ and ionic strength, the solubility of Th(IV) hydroxide may be as high as $0.5-1 \mathrm{nmol} / \mathrm{kg}$, compared to $1 \mathrm{fmol} / \mathrm{kg}$ for crystalline $\mathrm{ThO}_{2}$, due to the amorphous nature of $\mathrm{Th}(\mathrm{OH})_{4}$ solids (Neck et al., 2003). Also, electrochemical methods suggest organic Th ligands exist at nanomolar concentrations (Hirose, 2004). Despite our finding of low colloidal Th content, organically-bound Th could of course be present at Station ALOHA if the complexes are smaller than $\sim 10 \mathrm{~nm}$. We advocate direct measurements of Th solubility in seawater, perhaps using radio-tracer additions with similar protocols as developed for Fe (Kuma et al., 1996; Schlosser and Croot, 2008), to confirm that Th exists in the deep ocean at much less than its equilibrium solubility. This would explain the fact that dissolved Th concentrations continue to grow from lithogenic sources in the deep North Pacific, where Fe concentrations become fixed by a solubility limit.

\section{Conclusions}

Using time-series data from the North Pacific, this study finds variability in surface Fe and ${ }^{232}$ Th concentrations consistent with a source from Asian dust. The dust source likely has a 
575 inventories allows the accurate evaluation of the flux of dissolved metals from dust in the remote

576 surface ocean. The source flux of dissolved Fe, derived from ${ }^{230}$ Th-based timescales, suggests

577 that dissolved Fe in the upper $250 \mathrm{~m}$ is turning over in 1 year or less. A compelling implication

578 of this result is that Fe delivery to phytoplankton can be expected to vary with seasonal-to-

579 interannual changes in dust delivery from Asia. Continued monitoring of Fe-dependent

580 biological processes, such as nitrogen fixation, are crucial to anticipate the consequences of

581 changing land-use and/or industrial processes that may significantly affect eolian sources of Fe

582 to the North Pacific.

583

In addition, by comparing Fe and Th size-partitioning, we find evidence that colloidal Fe

584 may be of predominantly organic composition in the subtropical North Pacific. We also

585 hypothesize that iron reaches a solubility limit in the deep sea $(>2 \mathrm{~km})$ while Th does not. While

586 less controversial for Th, this result questions the relevance of "excess" Fe ligands in the deep

587 sea. Overall, however, the kinetic box model approach to tracing dust-derived elements (Fig. 1)

588 appears well-suited in the upper water column $(\sim 250 \mathrm{~m})$.

589 Acknowledgements

590 We acknowledge funding from the W.O. Crosby Postdoctoral Fellowship to CTH and the 591 National Science Foundation through C-MORE, NSF-OIA EF-0424599 to EAB, and NSF-DMR

5921157490 supported RW and PLM. Soumen Mallick and Alberto Saal are thanked for facilitating 593 mass spectrometry performed at Brown University. Major thanks go to Tara Clemente and Sam

594 Wilson for their leadership roles on C-MORE cruises, and to Rick Kayser, Gonzalo Carrasco, 595 Abigail Noble, Simone Moos, Mengli Chen, and Rene Boiteau for their help in collecting 596 samples returned to MIT. The associate editor, Timothy Shaw, an anonymous reviewer, and 597 Michiel Rutgers van der Loeff are thanked for their constructive evaluations of the manuscript. 
600 Figure 1. Tracing the Fe cycle with the behavior of the long-lived thorium isotopes. Thorium230 has a well-known source from the radioactive decay of its parent ${ }^{234} \mathrm{U}$. This allows a quantitative estimate of Th removal due to scavenging on to particles. This removal rate can be used to estimate the steady-state source of ${ }^{232}$ Th from the partial dissolution of aerosol dust, assuming dust dissolution and scavenging dominate the Th cycle which may be most relevant in the remote surface ocean. While Fe has many more terms in its biogeochemical cycling, its ultimate source from dust dissolution can be predicted using known ${ }^{232} \mathrm{Th}$ fluxes and the relative solubility of $\mathrm{Fe}$ and $\mathrm{Th}$. Assuming Fe is derived only from dust, one can then estimate a maximum Fe residence time or minimum turnover rate.

Figure 2. Depth profiles from the Hawaii Ocean Time-series Station ALOHA from sampling campaigns in 2012-2013. In July 2012 and June 2013, profiles for dissolved ${ }^{232} \mathrm{Th}$ (A) and ${ }^{230} \mathrm{Th}$ (B) were collected in two casts (shallow to $250 \mathrm{~m}$ and deep to $1500 \mathrm{~m}$ ) on different days. Relative uncertainty in isotope concentrations was 1-5\% and thus errors bars would be close to the symbol size. The hydrographic profiles $(\mathrm{C}-\mathrm{F})$ are shown from the shallow cast only.

Figure 3. Thorium residence times, or turnover rates, calculated for the upper $150 \mathrm{~m}$ at Station ALOHA on a monthly axis combining data from 1999 to 2014. These times are calculated by comparing integrated Th inventories to integrated production by uranium decay. The ${ }^{234} \mathrm{Th}-\mathrm{based}$ results are reported by Buesseler et al. (2009) and Benitez-Nelson et al. (2001). Note the ${ }^{230}$ Thbased results from March 2014 are not based on profiles but on single samples from $25 \mathrm{~m}$, assuming uniform concentrations in the upper 150 as seen in the 2012-2013 profiles (Fig. 2).

Figure 4. Station ALOHA time-series data from the surface ocean (0-10 meters depth) on dissolved (filtered at 0.45 or $0.4 \mu \mathrm{m}$ ), total (unfiltered) and particulate (digested $0.4 \mu \mathrm{m}$ filter) ${ }^{232}$ Th in full time-series (1994-2014) (A), monthly climatology (1991-2014) (B) and during a daily resolution period in July-Sept. 2012 (C). Note change in scale of y-axes at $160 \mathrm{fmol} / \mathrm{kg}$. Results from 1994 were reported by Roy-Barman et al. (1996). Open circles represent samples collected using a mooring rather than ship-based sampling (Sec. 4.1). Relative uncertainty in dissolved, total and particulate ${ }^{232} \mathrm{Th}$ concentrations was $1-10 \%$.

Figure 5. Station ALOHA time-series data from the surface ocean (0-10 meters depth) (A), monthly climatology (B) and a daily resolution period in July-Sept. 2012 (C) of the dissolved (filtered at 0.45 or $0.4 \mu \mathrm{m}$ ), total (unfiltered) and particulate (digested $0.4 \mu \mathrm{m}$ filter) $\mathrm{Fe} /{ }^{232} \mathrm{Th}$ ratio. Note change in scale of $\mathrm{y}$-axes at $25,000 \mathrm{~mol} / \mathrm{mol}$. The dotted lines represent the $\mathrm{Fe} /{ }^{232} \mathrm{Th}$ ratio of Asian dust of $10,800 \pm 1,200 \mathrm{~mol} / \mathrm{mol}(1 \sigma)$. Note in $(\mathrm{C})$, four samples with particulate $\mathrm{Fe} /{ }^{232} \mathrm{Th}$ ratios greater than 40,000 are not shown. Open circles represent samples collected using a mooring rather than ship-based sampling (Sec. 4.1).

Figure 6. Depth profiles of the percentage of dissolved metals $(<0.45 \mu \mathrm{m}$ for Th or $<0.4 \mu \mathrm{m}$ for $\mathrm{Fe}$ ) that are in the colloidal size fraction (roughly 10-400 nm) from Station ALOHA in late September 2013. Colloidal content is estimated by subtracting the metal concentration in $0.4 \mu \mathrm{m}$ filtered seawater (dissolved) from that passing through a $10 \mathrm{kDa}$ membrane filter by cross-flow filtration (soluble). Colloidal fractions of ${ }^{232} \mathrm{Th}$ and ${ }^{230} \mathrm{Th}$ agree within uncertainties, while Fe

644 colloidal content is 2-3 times larger. 
645

646

647

648

649

650

651

652

653

654

655

656

657

658

659

660

661

662

663

664

665

666

667

668

669

670

671

672

673

674

675

676

677

678

679

680

681

682

683

684

685

686

Figure 7. Application of dissolved ${ }^{232} \mathrm{Th}$ fluxes to predict the residence time of dissolved $\mathrm{Fe}$ in seawater at Station ALOHA during 2012-2013. Dissolved Th residence times (A) are calculated as a function of integration depth using radioactive disequilibrium between ${ }^{234} \mathrm{U}$ and ${ }^{230} \mathrm{Th}$. Integrated values shallower than the deep chlorophyll maximum $(\sim 120 \mathrm{~m})$ are not included on the assumption that steady-state Th scavenging may not apply within the euphotic zone. The integrated ${ }^{232} \mathrm{Th}$ inventories divided by these residence times produces an estimate of the dissolved ${ }^{232}$ Th flux (B) due to dust dissolution. Assuming equal fractional solubilities dissolution and a near crustal composition for Asian dust, the flux of dissolved Fe from dust can be predicted using the second $\mathrm{x}$-axis in (B). The integration of dissolved Fe inventories based on concentration profiles shown in (C) (Fitzsimmons et al., in review), produces our estimate of dissolved Fe residence time in $(\mathrm{D}$, note change in scale of $\mathrm{x}$-axis at $1.2 \mathrm{yrs})$.

Figure 8. Full ocean depth profiles from Station ALOHA for dissolved Fe (A), ${ }^{232} \mathrm{Th}(\mathrm{B})$ and ${ }^{230} \mathrm{Th}$ (C) using data from this study (July 2012) and compiled from the literature. Iron data from April 2001 and July 2002 were reported by Boyle et al. (2005) and from June 2002 by Morton (2010). Dissolved Th data from 1994 were reported by Roy-Barman et al. (1996). Note in (C) the dotted grey line is the linear regression of ${ }^{230}$ Th data between 1 and $3.5 \mathrm{~km}$, which when extended to the seafloor demonstrates that the bottom two samples are less than expected from reversible scavenging and imply enhanced scavenging (assuming no other processes affect supply and removal of ${ }^{230}$ Th here).

Figure 9. Application of dissolved ${ }^{232}$ Th fluxes to predict Fe residence times for the full depth ocean at Station ALOHA. Here data from July 2012 are used to calculate ${ }^{232}$ Th fluxes (A). The depth profiles of Fe concentrations presented in Fig. 8 were averaged to calculate the dissolved Fe residence times as a function of integration depth (B). The 30 year ocean residence for dissolved Fe is significantly lower than the century-scale residence times derived by other approaches, suggesting that ${ }^{232} \mathrm{Th}$ flux may not be an accurate proxy for Fe sources in the deep ocean.

\section{References}

Andersen, M.B., Stirling, C.H., Zimmermann, B. and Halliday, A.N. (2010) Precise determination of the open ocean ${ }^{234} \mathrm{U} /{ }^{238} \mathrm{U}$ composition. Geochem. Geophys. Geosyst. 11, Q12003.

Anderson, R.F., Fleisher, M.Q., Robinson, L.F., Edwards, R.L., Hoff, J., Moran, S.B., Rutgers van der Loeff, M.M., Thomas, A.L., Roy-Barman, M. and François, R. (2012) GEOTRACES intercalibration of ${ }^{230} \mathrm{Th},{ }^{232} \mathrm{Th},{ }^{231} \mathrm{~Pa}$, and prospects for ${ }^{10} \mathrm{Be}$. Limnol. Oceanogr. Methods 10, 179-213.

Andersson, P.S., Wasserburg, G.J., Chen, J.H., Papanastassiou, D.A. and Ingri, J. (1995) ${ }^{238} \mathrm{U}_{-}{ }^{234} \mathrm{U}_{\text {and }}$ ${ }^{232} \mathrm{Th}^{230} \mathrm{Th}$ in the Baltic Sea and in river water. Earth Planet. Sci. Lett. 130, 217-234.

Auro, M.E., Robinson, L.F., Burke, A., Bradtmiller, L.I., Fleisher, M.Q. and Anderson, R.F. (2012) Improvements to 232-thorium, 230-thorium, and 231-protactinium analysis in seawater arising from GEOTRACES intercalibration. Limnol. Oceanogr. Methods 10, 464-474. 
687 Bacon, M.P. and Anderson, R.F. (1982) Distribution of thorium isotopes between dissolved and 688 particulate forms in the deep sea. J. Geophys. Res. 87, 2045-2056.

689 Barbeau, K., Kujawinski, E.B. and Moffett, J.W. (2001) Remineralization and recycling of iron, thorium and organic carbon by heterotrophic marine protists in culture. Aquat. Microb. Ecol. 24, 69-81.

691 Barone, B., Bidigare, R.R., Church, M.J., Karl, D.M., Letelier, R.M. and White, A.E. (2015) Particle 692 distributions and dynamics in the euphotic zone of the North Pacific Subtropical Gyre. Journal of 693 Geophysical Research: Oceans, Available online http://dx.doi.org/10.1002/2015JC010774.

694 Bell, J., Betts, J. and Boyle, E. (2002) MITESS: a moored in situ trace element serial sampler for deep-sea 695 moorings. Deep-Sea Res. I 49, 2103-2118.

Benitez-Nelson, C., Buesseler, K.O., Karl, D.M. and Andrews, J. (2001) A time-series study of particulate matter export in the North Pacific Subtropical Gyre based on ${ }^{234} \mathrm{Th}:{ }^{238} \mathrm{U}$ disequilibrium. DeepSea Res. I 48, 2595-2611.

700

Bergquist, B.A. and Boyle, E.A. (2006) Dissolved iron in the tropical and subtropical Atlantic Ocean. Global Biogeochem. Cycles 20, GB1015.

701 Bishop, J.K.B. and Wood, T.J. (2008) Particulate matter chemistry and dynamics in the twilight zone at 702 VERTIGO, ALOHA and K2 sites. Deep-Sea Res. I 55, 1684-1706.

Boyd, P.W., Mackie, D.S. and Hunter, K.A. (2010) Aerosol iron deposition to the surface ocean Modes of iron supply and biological responses. Mar. Chem. 120, 128-143.

Boyle, E.A., Bergquist, B.A., Kayser, R.A. and Mahowald, N. (2005) Iron, manganese, and lead at Hawaii Ocean Time-series station ALOHA: Temporal variability and an intermediate water hydrothermal plume. Geochim. Cosmochim. Acta 69, 933-952.

Bressac, M. and Guieu, C. (2013) Post-depositional processes: What really happens to new atmospheric iron in the ocean's surface? Global Biogeochem. Cycles 27, 859-870.

Bruland, K.W., Orians, K.J. and Cowen, J.P. (1994) Reactive trace metals in the stratified central North Pacific. Geochim. Cosmochim. Acta 58, 3171-3182.

Buesseler, K.O., Bacon, M.P., Kirk Cochran, J. and Livingston, H.D. (1992) Carbon and nitrogen export during the JGOFS North Atlantic Bloom experiment estimated from ${ }^{234} \mathrm{Th}:{ }^{238} \mathrm{U}$ disequilibria. Deep-Sea Res. A 39, 1115-1137. a tracer of spatial, temporal and vertical variability in particle flux in the North Pacific. Deep-Sea Res. I 56, 1143-1167.

Charette, M.A., Breier, C.F., Henderson, P.B., Pike, S.M., Rypina, I.I., Jayne, S.R. and Buesseler, K.O. (2013) Radium-based estimates of cesium isotope transport and total direct ocean discharges from the Fukushima Nuclear Power Plant accident. Biogeosciences 10, 2159-2167.

721 Cheng, H., Edwards, R.L., Shen, C.-C., Polyak, V.J., Asmerom, Y., Woodhead, J., Hellstrom, J., Wang, 722 Y., Kong, X., Spötl, C., Wang, X. and Calvin Alexander Jr, E. (2013) Improvements in ${ }^{230}$ Th dating, ${ }^{230}$ Th 
and ${ }^{234} \mathrm{U}$ half-life values, and U-Th isotopic measurements by multi-collector inductively coupled plasma mass spectrometry. Earth Planet. Sci. Lett. 371-372, 82-91.

Church, M.J., Lomas, M.W. and Muller-Karger, F. (2013) Sea change: Charting the course for biogeochemical ocean time-series research in a new millennium. Deep-Sea Res. II 93, 2-15.

Coale, K.H. and Bruland, K.W. (1985) ${ }^{234}$ Th: ${ }^{238} \mathrm{U}$ disequilibria within the California Current. Limnol. Oceanogr. 30, 22-33.

Conway, T.M. and John, S.G. (2014) Quantification of dissolved iron sources to the North Atlantic Ocean. Nature 511, 212-215.

Dammshäuser, A. and Croot, P.L. (2012) Low colloidal associations of aluminium and titanium in surface waters of the tropical Atlantic. Geochim. Cosmochim. Acta 96, 304-318.

Dammshäuser, A., Wagener, T., Garbe-Schönberg, D. and Croot, P. (2013) Particulate and dissolved aluminum and titanium in the upper water column of the Atlantic Ocean. Deep-Sea Res. I 73, 127-139.

Deng, F., Thomas, A.L., Rijkenberg, M.J.A. and Henderson, G.M. (2014) Controls on seawater ${ }^{231} \mathrm{~Pa}$, ${ }^{230} \mathrm{Th}$ and ${ }^{232} \mathrm{Th}$ concentrations along the flow paths of deep waters in the Southwest Atlantic. Earth Planet. Sci. Lett. 390, 93-102.

Edwards, R.L., Chen, J.H. and Wasserburg, G.J. (1987) ${ }^{238} \mathrm{U}_{-}{ }^{234} \mathrm{U}_{-}{ }^{230} \mathrm{Th}^{2}{ }^{232} \mathrm{Th}$ systematics and the precise measurement of time over the past 500,000 years. Earth Planet. Sci. Lett. 81, 175-192.

Fitzsimmons, J.N. and Boyle, E.A. (2014a) Assessment and comparison of Anopore and cross flow filtration methods for the determination of dissolved iron size fractionation into soluble and colloidal phases in seawater. Limnol. Oceanogr. Methods 12, 246-263.

Fitzsimmons, J.N. and Boyle, E.A. (2014b) Both soluble and colloidal iron phases control dissolved iron variability in the tropical North Atlantic Ocean. Geochim. Cosmochim. Acta 125, 539-550.

Fitzsimmons, J.N., Hayes, C.T., al-Subiai, S., Morton, P.L., Weisend, R., Ascani, F. and Boyle, E.A. (in review) Daily to decadal variability of size-fractionated iron and iron-binding ligands at the Hawaii Ocean Time-series Station ALOHA. Geochim. Cosmochim. Acta.

Gledhill, M. and Buck, K.N. (2012) The organic complexation of iron in the marine environment: A review. Front. Microbiol. 3.

Guo, L. and Santschi, P.H. (2007) Ultrafiltration and its applications to sampling and characterisation of aquatic colloids. IUPAC Series on Analytical and Physical Chemistry of Environmental Systems 10, 159.

Guo, L., Santschi, P.H. and Baskaran, M. (1997) Interactions of thorium isotopes with colloidal organic matter in oceanic environments. Colloids Surf. A 120, 255-271.

Hayes, C.T., Anderson, R.F., Fleisher, M.Q., Huang, K.-F., Robinson, L.F., Lu, Y., Cheng, H., Edwards, R.L. and Moran, S.B. (2015a) ${ }^{230} \mathrm{Th}$ and ${ }^{231} \mathrm{~Pa}$ on GEOTRACES GA03, the U.S. GEOTRACES North Atlantic transect, and implications for modern and paleoceanographic chemical fluxes. Deep-Sea Res. II $116,29-41$. 
Hayes, C.T., Anderson, R.F., Fleisher, M.Q., Serno, S., Winckler, G. and Gersonde, R. (2013a) Quantifying lithogenic inputs to the North Pacific Ocean using the long-lived thorium isotopes. Earth Planet. Sci. Lett. 383, 16-25.

Hayes, C.T., Anderson, R.F., Fleisher, M.Q., Vivancos, S.M., Lam, P.J., Ohnemus, D.C., Huang, K.-F., Robinson, L.F., Lu, Y., Cheng, H., Edwards, R.L. and Moran, S.B. (2015b) Intensity of Th and Pa scavenging partitioned by particle chemistry in the North Atlantic Ocean. Marine Chemistry 170, 49-60.

Hayes, C.T., Anderson, R.F., Jaccard, S.L., François, R., Fleisher, M.Q., Soon, M. and Gersonde, R. (2013b) A new perspective on boundary scavenging in the North Pacific Ocean. Earth Planet. Sci. Lett. 369-370, 86-97.

Hirose, K. (2004) Chemical Speciation of Thorium in Marine Biogenic Particulate Matter. TheScientificWorldJOURNAL 4, 67-76.

Hirose, K. and Tanoue, E. (1994) Thorium-particulate matter interaction. Thorium complexing capacity of oceanic particulate matter: Theory. Geochim. Cosmochim. Acta 58, 1-7.

Ho, T.-Y., Chou, W.-C., Lin, H.-L. and Sheu, D.D. (2011) Trace metal cycling in the deep water of the South China Sea: The composition, sources, and fluxes of sinking particles. Limnol. Oceanogr. 56, 12251243.

Honeyman, B.D., Balistrieri, L.S. and Murray, J.W. (1988) Oceanic trace metal scavenging: the importance of particle concentration. Deep-Sea Res. A 35, 227-246.

Honeyman, B.D. and Santschi, P.H. (1989) A Brownian-pumping model for oceanic trace metal scavenging: Evidence from Th isotopes. J. Mar. Res. 47, 951-992.

Hsieh, Y.-T., Henderson, G.M. and Thomas, A.L. (2011) Combining seawater ${ }^{232}$ Th and ${ }^{230}$ Th concentrations to determine dust fluxes to the surface ocean. Earth Planet. Sci. Lett. 312, 280-290.

Huh, C.-A. and Prahl, F.G. (1995) Role of colloids in upper ocean biogeochemistry in the northeast Pacific Ocean elucidated from ${ }^{238} \mathrm{U}_{-}{ }^{234} \mathrm{Th}$ disequilibria. Limnol. Oceanogr. 40, 528-528.

Hyslop, N.P., Trzepla, K., Wallis, C.D., Matzoll, A.K. and White, W.H. (2013) Technical note: A 23-year record of twice-weekly aerosol composition measurements at Mauna Loa Observatory. Atmos. Environ. 80, 259-263.

Jickells, T.D. (1999) The inputs of dust derived elements to the Sargasso Sea; a synthesis. Mar. Chem. 68, 5-14.

Jickells, T.D., An, Z.S., Andersen, K.K., Baker, A.R., Bergametti, G., Brooks, N., Cao, J.J., Boyd, P.W., Duce, R.A., Hunter, K.A., Kawahata, H., Kubilay, N., laRoche, J., Liss, P.S., Mahowald, N., Prospero, J.M., Ridgwell, A.J., Tegen, I. and Torres, R. (2005) Global iron connections between desert dust, ocean biogeochemistry, and climate. Science 308, 67-71.

Karl, D.M., Church, M.J., Dore, J.E., Letelier, R.M. and Mahaffey, C. (2012) Predictable and efficient carbon sequestration in the North Pacific Ocean supported by symbiotic nitrogen fixation. Proc. Natl. Acad. Sci. U. S. A. 
Karl, D.M. and Lukas, R. (1996) The Hawaii Ocean Time-series (HOT) program: Background, rationale and field implementation. Deep-Sea Res. II 43, 129-156.

Kitayama, S., Kuma, K., Manabe, E., Sugie, K., Takata, H., Isoda, Y., Toya, K., Saitoh, S.-i., Takagi, S., Kamei, Y. and Sakaoka, K. (2009) Controls on iron distributions in the deep water column of the North Pacific Ocean: Iron(III) hydroxide solubility and marine humic-type dissolved organic matter. J. Geophys. Res. 114, C08019.

Kuma, K., Isoda, Y. and Nakabayashi, S. (2003) Control on dissolved iron concentrations in deep waters in the western North Pacific: Iron(III) hydroxide solubility. J. Geophys. Res. 108, 3289.

Kuma, K., Nishioka, J. and Matsunaga, K. (1996) Controls on iron(III) hydroxide solubility in seawater: the influence of $\mathrm{pH}$ and natural organic chelators. Limnol. Oceanogr. 41, 396-407.

Lee, J.-M., Boyle, E.A., Echegoyen-Sanz, Y., Fitzsimmons, J.N., Zhang, R. and Kayser, R.A. (2011)

Analysis of trace metals $(\mathrm{Cu}, \mathrm{Cd}, \mathrm{Pb}$, and $\mathrm{Fe})$ in seawater using single batch nitrilotriacetate resin extraction and isotope dilution inductively coupled plasma mass spectrometry. Anal. Chim. Acta 686, 93 101.

Lehnert, K., Su, Y., Langmuir, C.H., Sarbas, B. and Nohl, U. (2000) A global geochemical database structure for rocks. Geochemistry, Geophysics, Geosystems 1, 1012.

Liu, X. and Millero, F.J. (2002) The solubility of iron in seawater. Mar. Chem. 77, 43-54.

Luo, S., Ku, T.-L., Kusakabe, M., Bishop, J.K.B. and Yang, Y.-L. (1995) Tracing particle cycling in the upper ocean with ${ }^{230} \mathrm{Th}$ and ${ }^{228} \mathrm{Th}$ : An investigation in the equatorial Pacific along $140^{\circ} \mathrm{W}$. Deep-Sea Res. II 42, 805-829.

Mahowald, N.M., Baker, A.R., Bergametti, G., Brooks, N., Duce, R.A., Jickells, T.D., Kubilay, N., Prospero, J.M. and Tegen, I. (2005) Atmospheric global dust cycle and iron inputs to the ocean. Global Biogeochem. Cycles 19, GB4025.

Martínez-García, A., Sigman, D.M., Ren, H., Anderson, R.F., Straub, M., Hodell, D.A., Jaccard, S.L., Eglinton, T.I. and Haug, G.H. (2014) Iron Fertilization of the Subantarctic Ocean During the Last Ice Age. Science 343, 1347-1350.

McCave, I.N. (1986) Local and global aspects of the bottom nepheloid layers in the world ocean. Neth. J. Sea Res. 20, 167-181.

McGee, D. (2009) Reconstructing and interpreting the dust record and probing the plumbing of Mono Lake. PhD dissert. Columbia University, New York, NY.

Mendez, J., Guieu, C. and Adkins, J. (2010) Atmospheric input of manganese and iron to the ocean: Seawater dissolution experiments with Saharan and North American dusts. Mar. Chem. 120, 34-43.

Moore, C.M., Mills, M.M., Arrigo, K.R., Berman-Frank, I., Bopp, L., Boyd, P.W., Galbraith, E.D., Geider, R.J., Guieu, C., Jaccard, S.L., Jickells, T.D., La Roche, J., Lenton, T.M., Mahowald, N.M., Maranon, E., Marinov, I., Moore, J.K., Nakatsuka, T., Oschlies, A., Saito, M.A., Thingstad, T.F., Tsuda, A. and Ulloa, O. (2013) Processes and patterns of oceanic nutrient limitation. Nature Geosci. 6, 701-710. 
830 Moran, S.B. and Buesseler, K.O. (1992) Short residence time of colloids in the upper ocean estimated 831 from ${ }^{238} \mathrm{U}-{ }^{234} \mathrm{Th}$ disequilibria. Nature $359,221-223$.

832 Morton, P.L. (2010) Trace metal biogeochemistry in the western North Pacific, PhD Dissert. Old 833 Dominion University, Norfolk, VA.

834 Morton, P.L., Landing, W.M., Hsu, S.-C., Milne, A., Aguilar-Islas, A.M., Baker, A.R., Bowie, A.R., 835 Buck, C.S., Gao, Y., Gichuki, S., Hastings, M.G., Hatta, M., Johansen, A.M., Losno, R., Mead, C., Patay, 836 M.D., Swarr, G., Vendermark, A. and Zamora, L.M. (2013) Methods for sampling and analysis of marine 837 aerosols: results from the 2008 GEOTRACES aerosol intercalibration experiment. Limnol. Oceanogr.

838 Methods 11, 62-78.

839 Neck, V., Altmaier, M., Müller, R., Bauer, A., Fanghänel, T. and Kim, J.-I. (2003) Solubility of 840 crystalline thorium dioxide. Radiochim. Acta 91.

841 Ohnemus, D.C. and Lam, P.J. (2015) Cycling of lithogenic marine particles in the US GEOTRACES 842 North Atlantic transect. Deep-Sea Res. II 116, 283-302.

843 Okubo, A., Obata, H., Gamo, T. and Yamada, M. (2012) ${ }^{230}$ Th and ${ }^{232}$ Th distributions in mid-latitudes of 844 the North Pacific Ocean: Effect of bottom scavenging. Earth Planet. Sci. Lett. 339-340, 139-150.

845 Owens, S.A., Buesseler, K.O. and Sims, K.W.W. (2011) Re-evaluating the ${ }^{238}$ U-salinity relationship in 846 seawater: Implications for the ${ }^{238} \mathrm{U}^{234}$ Th disequilibrium method. Mar. Chem. 127, 31-39.

847 Prospero, J.M., Savoie, D.L. and Arimoto, R. (2003) Long-term record of nss-sulfate and nitrate in 848 aerosols on Midway Island, 1981-2000: Evidence of increased (now decreasing?) anthropogenic 849 emissions from Asia. J. Geophy. Res. 108, 4019.

850 Reuer, M.K., Boyle, E.A. and Grant, B.C. (2003) Lead isotope analysis of marine carbonates and 851 seawater by multiple collector ICP-MS. Chem. Geol. 200, 137-153.

852 Richards, K.J. (1990) Physical processes in the benthic boundary layer. Philos. Trans. R. Soc. London, 853 Ser. A 331, 3-13.

854 Roy-Barman, M., Chen, J.H. and Wasserburg, G.J. (1996) ${ }^{230} \mathrm{Th}^{-232}{ }^{23}$ systematics in the central Pacific 855 Ocean: The sources and the fates of thorium. Earth Planet. Sci. Lett. 139, 351-363.

856 Roy-Barman, M., Coppola, L. and Souhaut, M. (2002) Thorium isotopes in the western Mediterranean 857 Sea: an insight into the marine particle dynamics. Earth Planet. Sci. Lett. 196, 161-174.

858 Roy-Barman, M., Lemaître, C., Ayrault, S., Jeandel, C., Souhaut, M. and Miquel, J.C. (2009) The 859 influence of particle composition on thorium scavenging in the Mediterranean Sea. Earth Planet. Sci. Lett. $860 \quad 286,526-534$.

861 Rubin, M., Berman-Frank, I. and Shaked, Y. (2011) Dust- and mineral-iron utilization by the marine 862 dinitrogen-fixer Trichodesmium. Nature Geosci. 4, 529-534.

863 Rue, E.L. and Bruland, K.W. (1995) Complexation of iron(III) by natural organic ligands in the Central 864 North Pacific as determined by a new competitive ligand equilibration/adsorptive cathodic stripping 865 voltammetric method. Mar. Chem. 50, 117-138. 
866 Santschi, P.H., Murray, J.W., Baskaran, M., Benitez-Nelson, C.R., Guo, L.D., Hung, C.C., Lamborg, C., 867 Moran, S.B., Passow, U. and Roy-Barman, M. (2006) Thorium speciation in seawater. Mar. Chem. 100, $868 \quad 250-268$.

869 Schlosser, C. and Croot, P. (2008) Application of cross-flow filtration for determining the solubility of 870 iron species in open ocean seawater. Limnol. Oceanogr. Methods 6, 630-642.

871 Serno, S., Winckler, G., Anderson, R.F., Hayes, C.T., McGee, D., Machalett, B., Ren, H., Straub, S.M., 872 Gersonde, R. and Haug, G.H. (2014) Eolian dust input to the Subarctic North Pacific. Earth Planet. Sci. 873 Lett. 387, 252-263.

874 Tagliabue, A., Aumont, O. and Bopp, L. (2014) The impact of different external sources of iron on the 875 global carbon cycle. Geophys. Res. Lett. 41, 2013 GL059059.

876 Taylor, S.R. and McLennan, S.M. (1995) The geochemical evolution of the continental crust. Rev. 877 Geophys. 33, 241-265.

878 Upadhyay, N., Majestic, B.J., Prapaipong, P. and Herckes, P. (2009) Evaluation of polyurethane foam, 879 polypropylene, quartz fiber, and cellulose substrates for multi-element analysis of atmospheric particulate 880 matter by ICP-MS. Anal. Bioanal. Chem. 394, 255-266.

881 Ussher, S.J., Achterberg, E.P., Powell, C., Baker, A.R., Jickells, T.D., Torres, R. and Worsfold, P.J. 882 (2013) Impact of atmospheric deposition on the contrasting iron biogeochemistry of the North and South 883 Atlantic Ocean. Global Biogeochem. Cycles 27, 1096-1107.

884 Ward, B.A., Dutkiewicz, S., Moore, C.M. and Follows, M.J. (2013) Iron, phosphorus, and nitrogen 885 supply ratios define the biogeography of nitrogen fixation. Limnol. Oceanogr. 58, 2059-2075. 


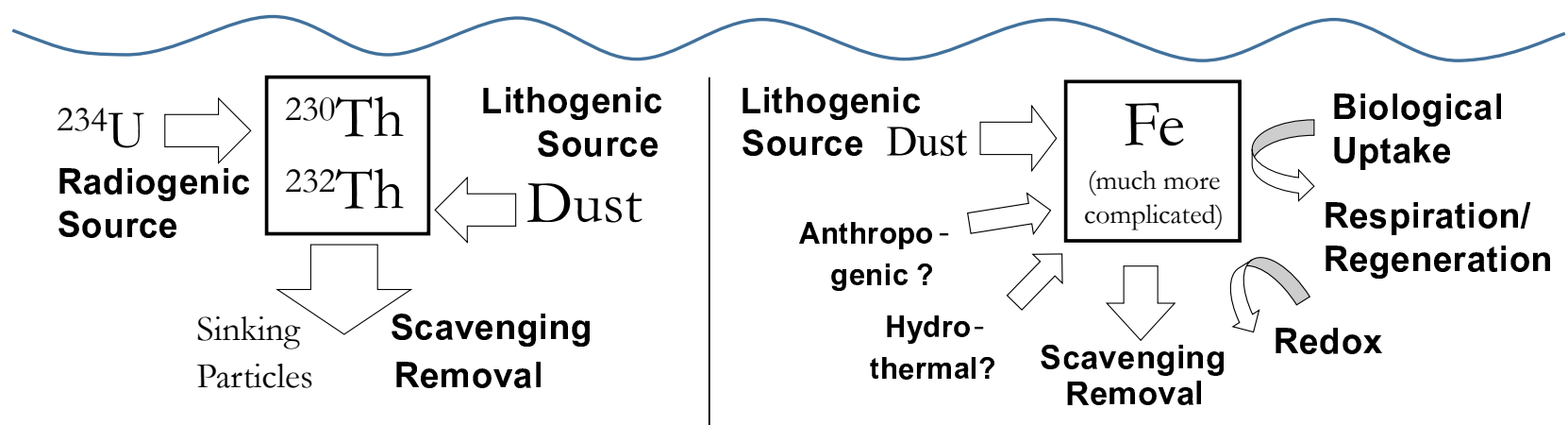




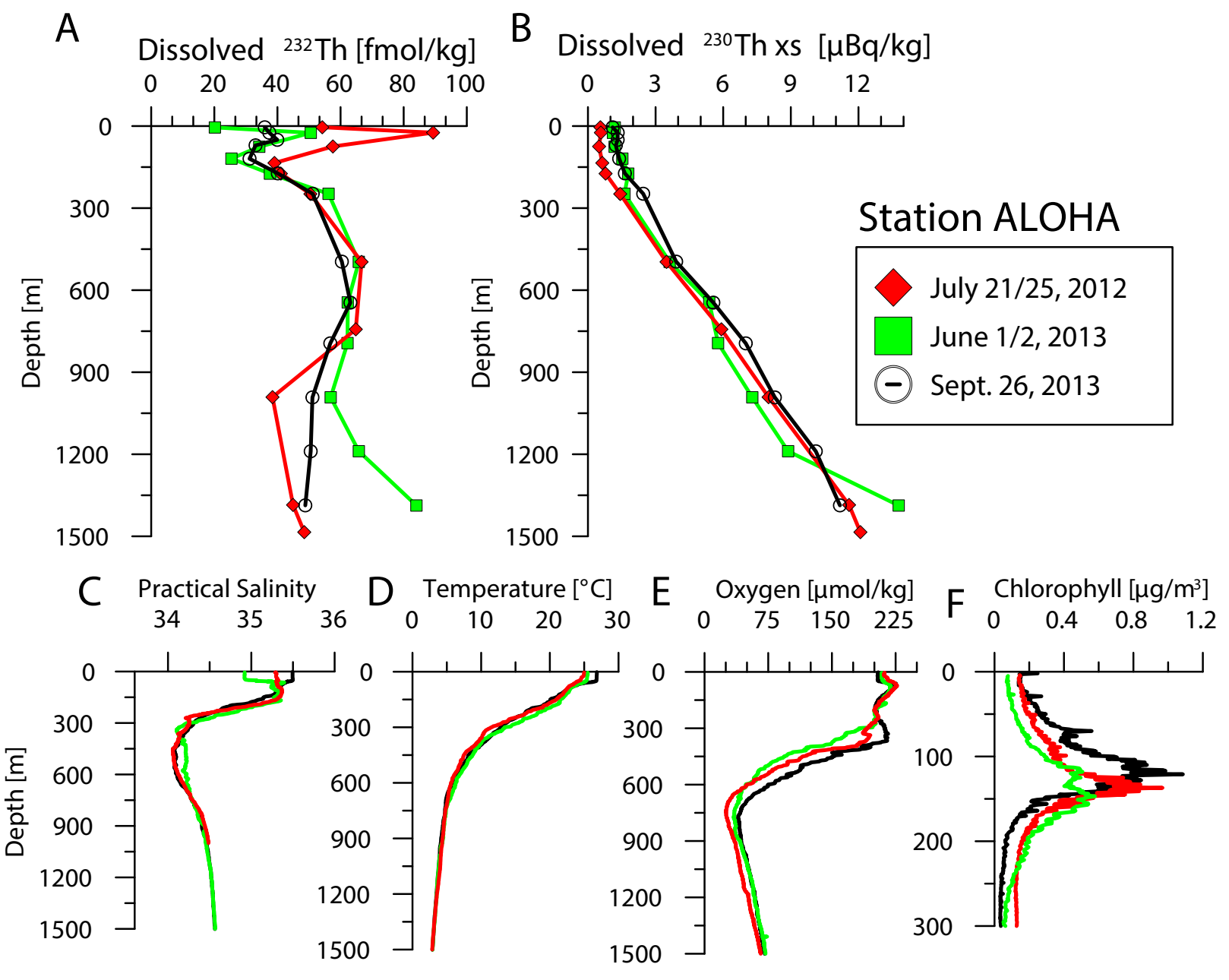




\section{Aqure 4}

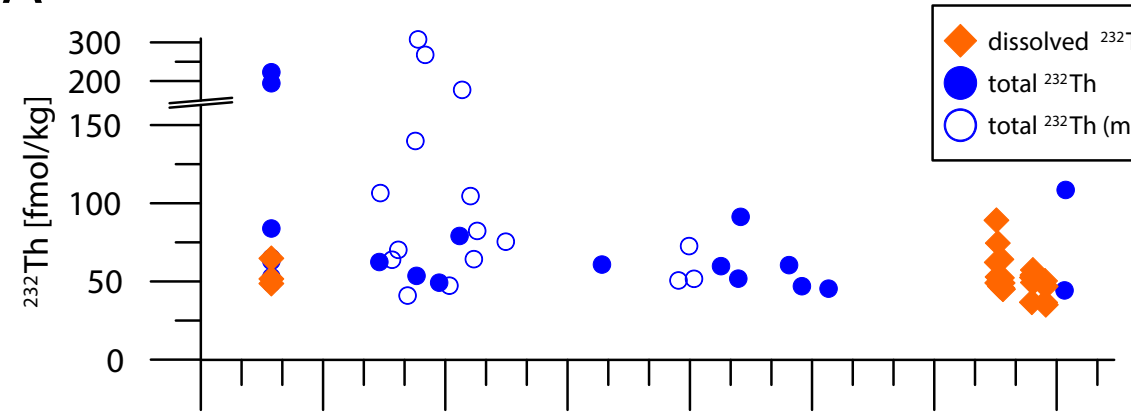

B $\begin{array}{llllllll}1993 & 1996 & 1999 & 2002 & 2005 & 2008 & 2011 & 2014\end{array}$

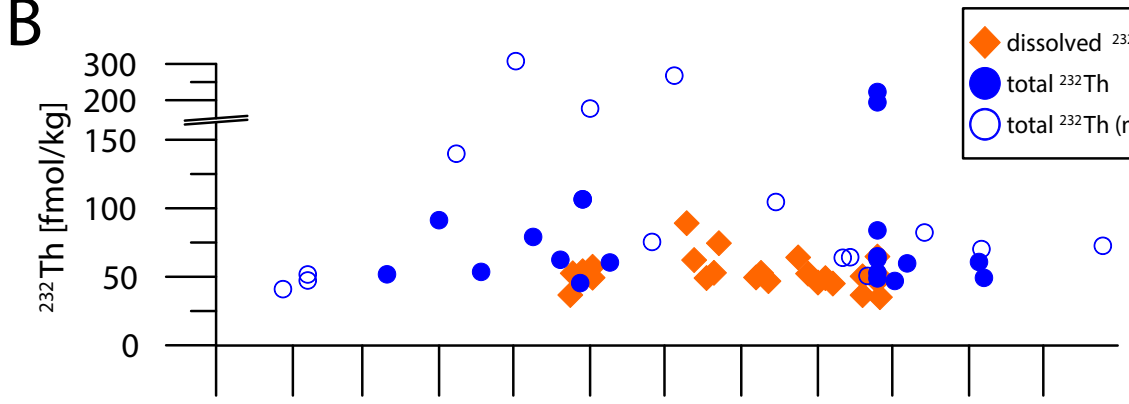

Jan Feb Mar Apr May Jun Jul Aug Sep Oct Nov Dec

C

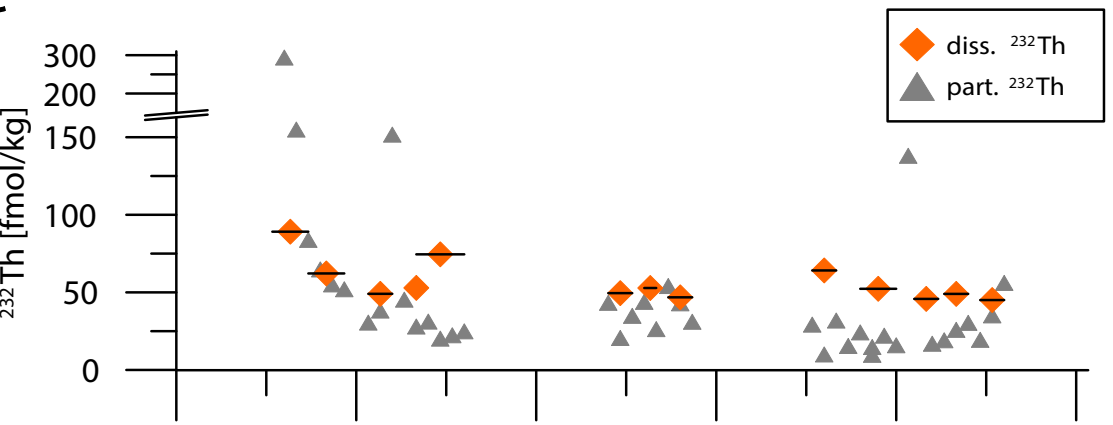

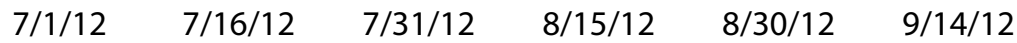


Figure $6 \%$ Colloidal metals (of dissolved)

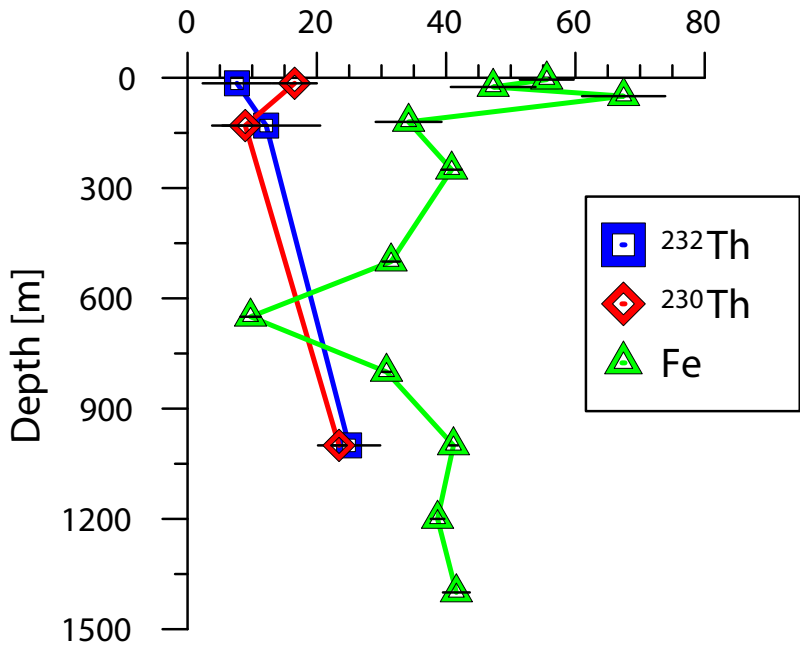


A

Diss. Th residence time [yrs]

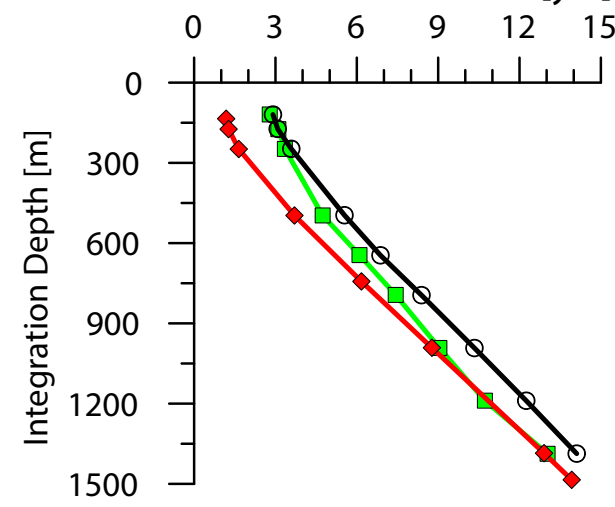

C

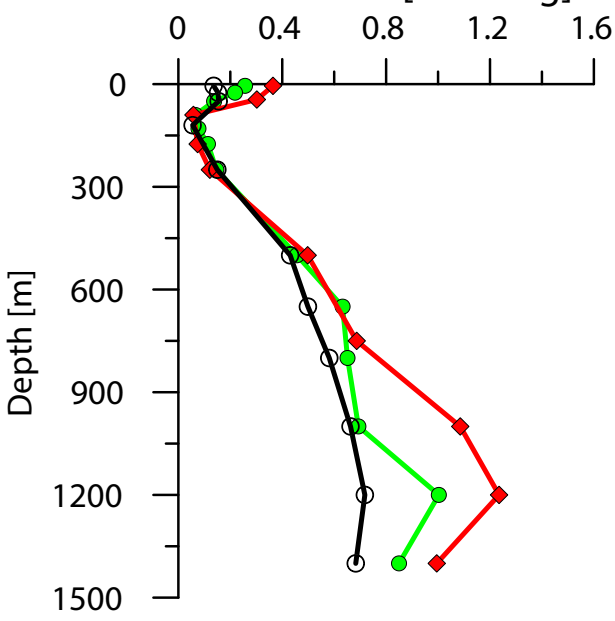

B Diss. ${ }^{232}$ Th Flux $\left[\mathrm{nmol} / \mathrm{m}^{2} / \mathrm{yr}\right]$

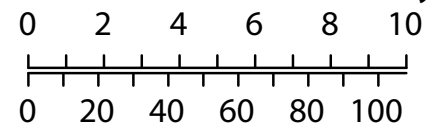

Dust-diss. Fe Flux $\left[\mu \mathrm{mol} / \mathrm{m}^{2} / \mathrm{yr}\right]$

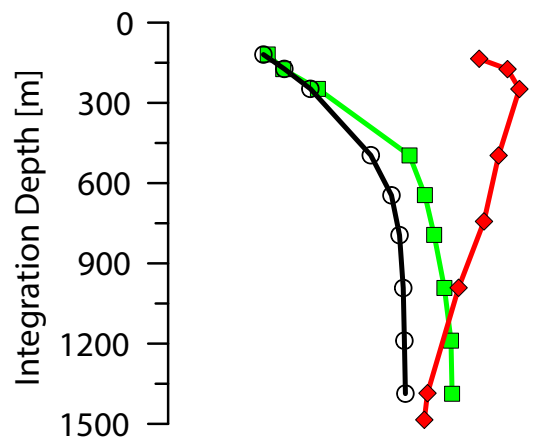

D Diss. Fe Residence Time [yrs]

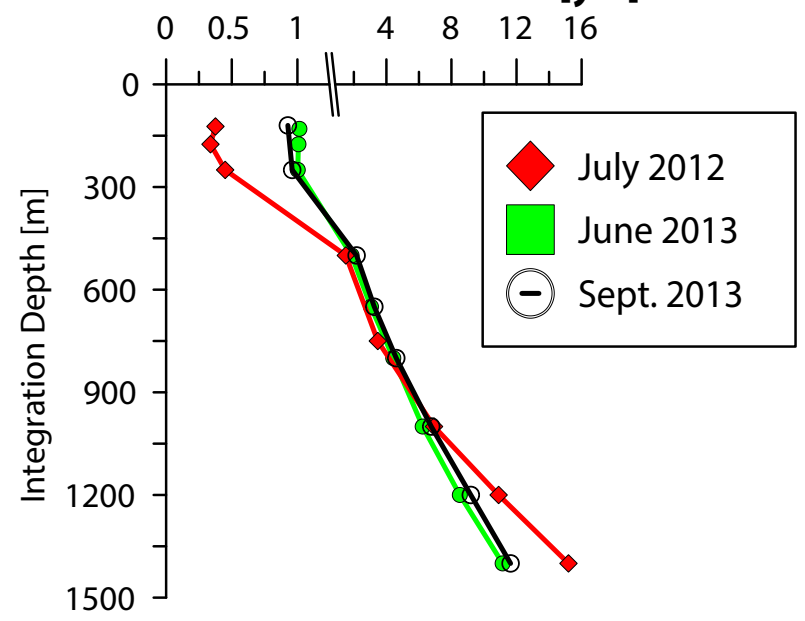




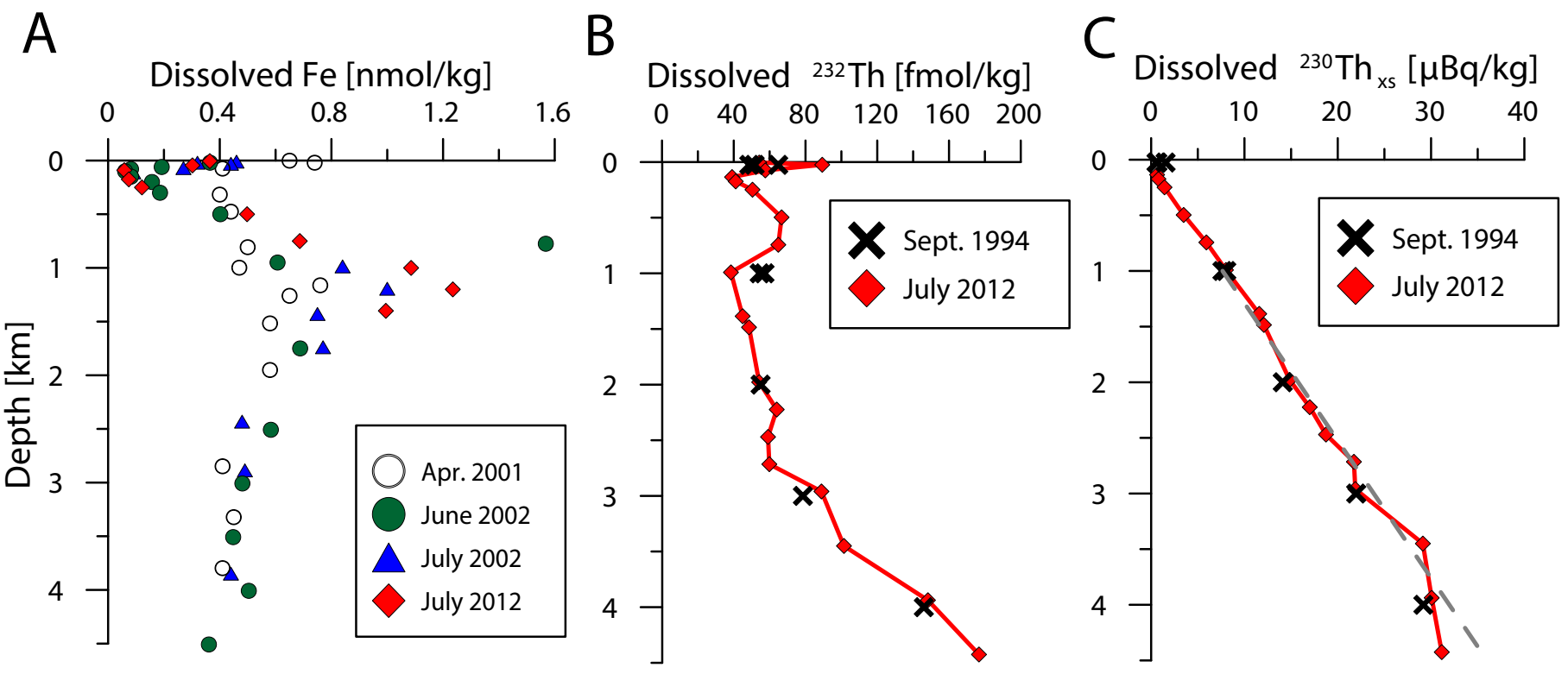


A

Diss. ${ }^{232} \mathrm{Th}$ Flux $\left[\mathrm{nmol} / \mathrm{m}^{2} / \mathrm{yr}\right]$

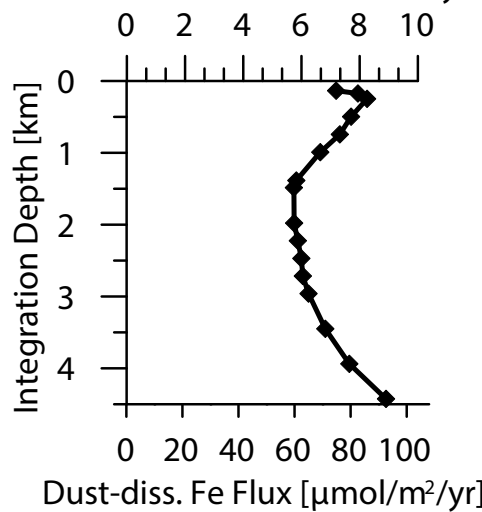

B

Diss. Fe Residence Time [yrs]

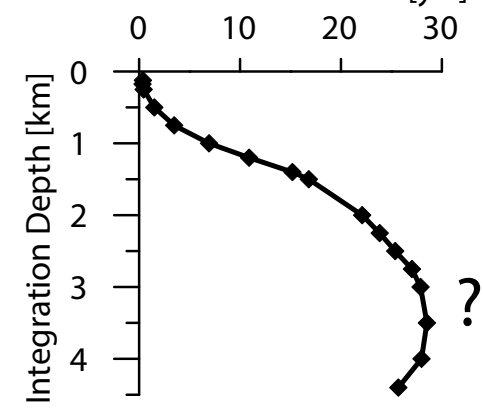

